\title{
Efeito da Adipocina Chemerin na ReAbsorção óssea em modelo experimental de Doença Periodontal e HIPERLIPIDEMIA
}

Tese apresentada à Faculdade de Odontologia de Ribeirão Preto da Universidade de São Paulo para obtenção de título de Doutor em Ciências.

Programa: Odontopediatria.

Área de concentração: Odontopediatria

Orientadora: Profa. Dra. Sandra Yasuyo Fukada Alves

Ribeirão Preto 


\section{AUTORIZAÇÃo PARA REPROdUÇÃo}

Autorizo a reprodução e/ou divulgação total da presente obra, por qualquer meio convencional ou eletrônico, para fins de estudo e pesquisa, desde que citada a fonte.

FICHA CATALOGRÁFICA

Guerreiro, Giselle de Angelo Leite Carbonaro

Efeito da adipocina chemerin na reabsorção óssea em modelo experimental de doença periodontal e hiperlipidemia. Ribeirão Preto, 2015. 103p. : il. ; $30 \mathrm{~cm}$

Tese de Doutorado apresentada à Faculdade de Odontologia de Ribeirão Preto/USP - Área de Concentração: Odontopediatria.

Orientadora: Alves, Sandra Yasuyo Fukada

1. Doença periodontal; 2. Hiperlipidemia; 4. Adipocina chemerin 
Guerreiro, Galc. Efeito da Adipocina Chemerin na Reabsorção Óssea em Modelo Experimental de Doença Periodontal e Hiperlipidemia. [Tese de Doutorado] Ribeirão Preto (SP): Faculdade de Odontologia de Ribeirão Preto Universidade de São Paulo; 2015.

Tese apresentada à Faculdade de Odontologia de Ribeirão Preto da Universidade de São Paulo, para obtenção do Título de Doutor em Ciências.

Área de Concentração: Odontopediatria.

Data da defesa:

\section{Banca Examinadora}

Prof. Dr.

Titulação:

Julgamento: Assinatura:

Prof. Dr.

Titulação:

Julgamento: Assinatura:

Prof. Dr.

Titulação:

Julgamento:

Assinatura:

Prof. Dr.

Titulação:

Julgamento:

Assinatura:

Prof. Dr.

Titulação:

Julgamento: Assinatura: 



\section{DADOS CURRICULARES}

\section{GISELLE DE ANGELO LEITE CARBONARO GUERREIRO}

Nascimento 13 de dezembro de 1982 - Barretos/SP

Filiação Maura de Angelo Leite

Ademir de Souza Leite

2003-2006 Graduação em Odontologia

Faculdade de Odontologia de Ribeirão Preto da Universidade se São Paulo

- FORP/USP

2005-2006 Iniciação Científica (Bolsista PibiC- CNPq)

2007-2008 Curso de Pós-Graduação em Odontopediatria, nível Mestrado

(Bolsista FAPESP)

Faculdade de Odontologia de Ribeirão Preto - USP

2011-2011 Especialização em Odontopediatria

Conselho Federal de Odontologia

2012-2013 Especialização em Saúde da Família

(UnA-SUS)Universidade Federal de São Paulo - UNIFESP

2010-2013 Curso de Pós-Graduação em Odontopediatria, nível Doutorado

(Bolsista CAPES - 2010-2011)

Faculdade de Odontologia de Ribeirão Preto - USP

2012-atual Cirurgiã-dentista da Prefeitura Municipal de São Joaquim da Barra 



\title{
DEDICATÓRIA
}

\begin{abstract}
À Deus, pela dádiva da vida, por ter me ajudado a manter a fé nos momentos mais difíceis e pela graça de ter permitido concluir este trabalho!
\end{abstract}

Ao meu filho, Eduardo Leite Carbonaro Guerreiro, luz da minha vida! Dudu, quando você chegou, tornou a minha vida mais alegre e o meu mundo mais colorido! Obrigada por me dar forças para continuar e terminar este trabalho! Foi por você!

Te amo!

"... Sá se vê bem cam a caraçãa. @essencial é invisível aas alhas." (Antaine de Saint-Exupéry) 



\section{AGRADECIMENTOS ESPECIAIS}

Aos meus pais, Maura de Angelo Leite e Ademir de Souza Leite pelo incentivo constante, pelo amor incondicional e ajuda para a concretização deste sonho. Muito obrigada!

Ao meu marido, Beto Carbonaro, pela ajuda nos momentos dificeis e pelo companheirismo, principalmente durante os experimentos aos finais de semana e feriados. Obrigada por estar sempre ao meu lado!

À minha irmã, Juliana de Angelo Souza Leite, minha amiga que esta sempre disposta a me socorrer quando eu preciso. Obrigada pelo carinho e por fazer parte da minha vida!

À minha família, pelo carinho!

Aos meus amigos, obrigada por me incentivar e respeitar a minha ausência!

À minha orientadora Profa. Dra. Sandra Yasuyo Fukada Alves, obrigada pelo incentivo, apoio e pela paciência nos momentos difíceis! Sou muito grata pela ajuda, por ter acreditado em minha capacidade e pela forma como conduziu esta tese para que fosse possivel eu alcançar o meu objetivo. Não tenho palavras para agradecer! Muito obrigada! 

À Faculdade de Odontologia de Ribeirão Preto da Universidade de São Paulo, na pessoa do atual diretor Prof. Dr. Valdemar Mallet da Rocha Barros e da Vice-Diretora Profa. Dra. Léa Assed Bezerra da Silva, por contribuir para a minha formação.

À Coordenação do Curso de Pós-Graduação em Odontopediatria da Faculdade de Odontologia de Ribeirão Preto da Universidade de São Paulo, na pessoa da Coordenadora Profa. Dra. Léa Assed Bezerra da Silva e da Vice-Coordenadora Profa. Dra. Raquel Bezerra da Silva.

Aos Professores do Departamento de Clínica Infantil da Faculdade de Odontologia de Ribeirão Preto da Universidade de São Paulo, Prof. Dr. Paulo Nelson Filho, Profa. Dra. Maria Cristina Borsatto, Profa. Dra. Andiara De Rossi, Profa. Dra. Alexandra Mussolino de Queiroz, Profa. Dra. Aldevina Campos de Freitas, Profa. Dra. Sada Assed (in memorian), Prof. Dr. Mário Roberto Leonardo, Profa. Dra. Kranya Victória Diaz Serrano, Prof. Dr. Fabricio Kitazono de Carvalho. Vocês foram muito importantes na minha vida acadêmica.

Aos Professores da Disciplina de Ortodontia da Faculdade de Odontologia de Ribeirão Preto da Universidade de São Paulo Prof. Dr. Adilson Thomazinho, Prof. Dr. Fábio Lourenço Romano, Prof. Dr. José Tarcisio Lima Ferreira, Profa. Dra. Maria Bernadete Sasso Stuani e Profa. Dra. Mírian Aiko Nakane Matsumoto. Obrigada pelo conhecimento que foi compartilhado comigo durante o curso.

À Profa. Dra. Maria da Conceição Pereira Saraiva, professora da Disciplina de Epidemiologia da Faculdade de Odontologia de Ribeirão Preto da Universidade de São Paulo. 
À Profá. Dra. Sâmia Regiane Lourenço Joca da Faculdade de Ciências Farmacêuticas de Ribeirão Preto da Universidade de São Paulo, por ter aberto as portas do seu laboratório com muito carinho, para a realização de alguns experimentos.

À Profa. Dra. Márcia Regina Von Zeska Kress da Faculdade de Ciências Farmacêuticas de Ribeirão Preto da Universidade de São Paulo, por ter compartilhado comigo seus equipamentos para a quantificação de RNA.

A Profa. Dra. Ana Maria de Oliveira da Faculdade de Ciências Farmacêuticas de Ribeirão Preto da Universidade de Sao Paulo, por ter me recebido em seu laboratório sempre com muito carinho, me auxiliando em alguns experimentos.

Ao Prof. Dr Julio Scharfstein da universidade Federal do Rio de Janeiro por ter me concedido a cepa da bactéria utilizada no experimento.

Ao Prof. Dr. Sérgio Luiz de Souza Salvador da Faculdade de Ciências Farmacêuticas de Ribeirão Preto e Marina Del Arco por terem, com muito carinho, padronizado a cultura de bactérias.

Aos professores da banca, por terem aceito o convite e pela atenção dispensada na leitura da dissertação.

Aos funcionários do Departamento de Clínica Infantil da Faculdade de Odontologia de Ribeirão Preto da Universidade de São Paulo, Dr. Francisco Wanderley Garcia de Paula e Silva, Dra. Carolina Paes Torres Mantovani, Dra. Marilia Pacífico Lucisano, Nilza Letícia Magalhães, Marco Antônio dos Santos, Matheus Morelli Zanela, Micheli Cristina Leite Rovanholo, Filomena Leli Placciti, Fātima Aparecida Jacinto, Vera Ribeiro do Nascimento, Carmo Eurípedes Terra Barreto e José Aparecido Neves do Nascimento. 
Aos funcionários do Centro de Formação de Recursos Humanos Especializados no Atendimento Odontológico a Pacientes Especiais da Faculdade de Odontologia de Ribeirão Preto-USP, Benedita Viana Rodrigues, Renata A. Fernandes Rodrigues e Nadir das Dores Gardin.

Às funcionárias da Seção de Pós-Graduação da Faculdade de Odontologia de Ribeirão Preto da Universidade São Paulo, Isabel Cristina Galina Sola e Regiane Cristina Moi Sacilloto.

Às funcionárias do Departamento de Farmacologia da Faculdade de Ciências Farmacêuticas da Universidade de São Paulo.

Aos funcionários do Biotério da Faculdade de Odontologia de Ribeirão Preto da Universidade de São Paulo, Antônio Sérgio Aparecido Mesca, Aline Aparecida Ferraresi Tiballi e Antônio Massaro.

Aos funcionários do Biotério da Faculdade de Ciências Farmacêuticas de Ribeirão Preto da Universidade de São Paulo, Ronaldo de Araujo, Antonio Flávio Quintanilha Marongio, Fabio Junio Marsola, Reinaldo Fernando Batista, Lucas Oliveira Sousa, Sante Emmanuel Imai Carone.

Aos alunos do Programa de Pós-Graduação em Odontopediatria da Faculdade de Odontologia de Ribeirão Preto da Universidade de São Paulo.

Aos alunos do Programa de Pós-Graduação da Faculdade de Ciências Farmacêuticas de Ribeirão Preto da Universidade de São Paulo.

Aos amigas do laboratório, Lamis Ramadan, Leticia Andreotti Bignardi, Erivan Scharfstein è à Talita Pereira Prates pelo companheirismo e ajuda durante os experimentos. 
À Coordenação de Aperfeiçoamento de Pessoal de Nível Superior (CAPES) pela bolsa concedida.

À Prefeitura Municipal de São Joaquim da Barra por ter me permitido conciliar os horários de trabalho para terminar a tese. em especial, aos amigos do PSF Rosinha Basso pelo apoio e incentivo.

À todos que de alguma forma contribuíram para a realização deste sonho. Muito Obrigada!!

“... Cada pessaa que passa em nassa vida passa sazinha e nãa nas deixa sá parque deixa um panca de si e leva um panquinha de nás. Essa é a mais bela respansabilidade da vida e a prava de que as pessaas nãa se encantram par acasa" (Charles Chaplin) 
Guerreiro, GALC. Efeito da Adipocina Chemerin na Reabsorção Óssea em Modelo Experimental de Doença Periodontal e Hiperlipidemia . [Tese de Doutorado] Ribeirão Preto (SP): Faculdade de Odontologia de Ribeirão Preto - Universidade de São Paulo; 2015.

\section{RESUMO}

A periodontite é uma doença bucal infecto-inflamatória resultante da quebra da homeostase entre biofilme dentário e o hospedeiro. Diversos estudos tem mostrado que a obesidade e o sobrepeso são importantes fatores de risco para o desenvolvimento da doença periodontal. O tecido adiposo representa um reservatório de mediadores inflamatórios. A chemerin é uma adipocina secretada pelo tecido adiposo e atua em numerosos processos fisiológicos, como metabolismo, proliferação e diferenciação celular. Levando em consideração que alterações de adiposidade, observadas por medidas antropométricas, estão relacionadas com maior incidência de periodontite, e que chemerin, uma citocina produzida por adipócitos, está envolvida na resposta inflamatória, nota-se uma lacuna na literatura que correlacione o papel de chemerin na progressão da doença periodontal. Portanto, o presente projeto tem como objetivo avaliar a participação da adipocina chemerin no desenvolvimento da doença periodontal em camundongos hiperlipidêmicos e avaliar o efeito desta adipocina sobre a diferenciação e ativação de células ósseas. No estudo in vivo, os animais foram submetidos ao modelo experimental de hiperlipidemia e/ou periodontite e divididos em 4 grupos: Grupo I: camundongos controle. Grupo II: camundongos controle infectados pela Porphyromonas gingivalis $(P g)$. Grupo III: camundongos hiperlipidêmicos não infectados. Grupo IV: camundongos hiperlipidêmicos infectados pela $P g$. As amostras foram coletadas depois de 15, 30 e 60 dias. No estudo in vivo, o modelo de dieta hiperlipidêmica adotado foi eficaz em aumentar os níveis circulantes de colesterol e chemerin, embora não tenha alterado o peso dos animais. Observa-se ainda maior adiposidade corporal mostrada pelo aumento de peso dos tecidos adiposos retroperitoneal e epididimal dos animais hiperlipidêmicos. Na análise morfométrica foi observada uma maior perda óssea no grupo hiperlipidêmico quando comparado ao controle e essa perda óssea foi semelhante ao observado no animal infectado por $\mathrm{Pg}$. Foi observado que a expressão de chemerin na gengiva e plasma se correlacionam com marcadores de osteoclastos no tecido gengival e com a reabsorção alveolar. No estudo in vitro, foi observado que chemerin leva à maior formação de depósitos mineralizados em cultura de osteoblastos e maior reabsorção óssea em cultura de osteoclastos. Conclui-se que a hiperlipidemia provoca reabsorção óssea alveolar semelhante ao observado com infecção oral com $P$. gingivalis. Chemerin participa da reabsorção óssea alveolar visto que os níveis desta adipocina na gengiva e plasma se correlacionam com marcadores de osteoclastos no tecido gengival e com a reabsorção alveolar. Chemerin aumenta atividade de osteoblastos e osteoclastos in vitro.

PALAVRAS-CHAVE: doença periodontal, hiperlipidemia, adipocina chemerin. 

Guerreiro, GALC. The Adipokine Chemerin Effect on Bone Resorption in Experimental Model of Periodontal Disease and Hyperlipidemia. [Tese de Doutorado] Ribeirão Preto (SP): Faculdade de Odontologia de Ribeirão Preto - Universidade de São Paulo; 2015.

\begin{abstract}
Periodontitis is an infectious inflammatory oral disease resultant from the breaking of homeostasis between biofilm and the host. Several studies have shown that overweight and obesity are major risk factors for the development of periodontal disease. Adipose tissue is a reservoir of inflammatory mediators. The chemerin is an adipokine secreted by adipose tissue and acts in numerous physiological processes, such as metabolism, proliferation and differentiation. Considering that adiposity changes, observed by anthropometric measurements, are related to higher incidence of periodontitis, and chemerin, a cytokine produced by adipocytes, is involved in the inflammatory response, there is a gap in the literature that correlates the paper chemerin in the progression of periodontal disease. Therefore, this project aims to evaluate the participation of chemerin adipokine in the development of periodontal disease in hyperlipidemic mice and evaluate the effect of this adipokine on the differentiation and activation of bone cells. In the in vivo study, the animals underwent to the experimental model of hyperlipidemia and / or periodontitis and divided into 4 groups: Group I: control mice. Group II: control mice infected with Porphyromonas gingivalis $(P g)$. Group III: hyperlipidemic mice not infected. Group IV: hyperlipidemic mice infected by $P g$. Samples were collected after 15, 30 and 60 days. In the in vivo study, the model of hyperlipidemic diet adopted was effective in increasing circulating levels of cholesterol and chemerin, although it has not changed the weight of the animals. Greater body adiposity shown by the increased weight of the retroperitoneal and epididymal adipose tissues of hyperlipidemic animals was observed. In morphometric analysis, we observed an increased bone loss in hyperlipidemic group compared to the control and that this bone loss was similar to the observed in animals infected with $\mathrm{Pg}$. It was observed that the gum chemerin expression and plasma correlate with markers of osteoclast in the gingival tissue and alveolar resorption. In the in vitro study, it was observed that chemerin leads to increased formation of mineralized deposits in cultured osteoblasts and increased bone resorption in osteoclast culture. It concludes that hyperlipidemia causes alveolar bone resorption similar to that observed on oral infection with P. gingivalis. Chemerin participates in alveolar bone resorption, at the levels of this adipokine gum and plasma correlate with osteoclast markers in gingival tissue and alveolar resorption. Chemerin increases osteoblast activity and osteoclasts in vitro.
\end{abstract}

Keywords: periodontal disease, hyperlipidemia, adipokine chemerin. 



\section{LISTA DE TABELAS}

Tabela 1. Quadro comparativo de dieta.

Tabela 2. Concentração plasmática de colesterol total, triglicérides e glicose (15 dias) 55

Tabela 3. Concentração plasmática de colesterol total, triglicérides e glicose (30 dias)......

55

Tabela 4. Concentração plasmática de colesterol total, triglicérides e glicose (60

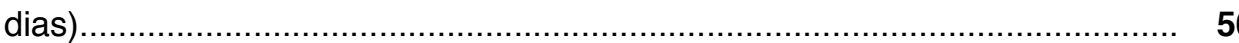

Tabela 5. Concentração plasmática de chemerin ……............................................... $\quad 60$ 



\section{LISTA DE FIGURAS}

Figura 1. Avaliação do peso corpóreo dos animais durante o período experimental......

Figura 2. Peso dos tecidos adiposos retroperitoneal e epididimal nos diferentes grupos experimentais......

Figura 3. Foto representativa da reabsorção óssea alveolar depois de 60 dias de infecção.

Figura 4. Análise macroscópica da reabsorção óssea alveolar........................... 57

Figura 5. Determinação da expressão gênica da adipocina chemerin........................ 58

Figura 6. Determinação da expressão gênica do receptor de chemerin - CMKLR-1..... 59

Figura 7. Determinação da expressão gênica de RANKL, OPG e catepsina K (60 dias).

Figura 8. Determinação da expressão gênica de TRAP...

Figura 9. Determinação da expressão gênica de osteocalcina................................. $\quad$ 61

Figura 10. Determinação da expressão gênica de ALP............................................. 62

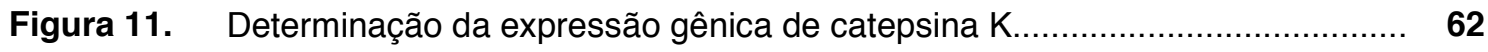

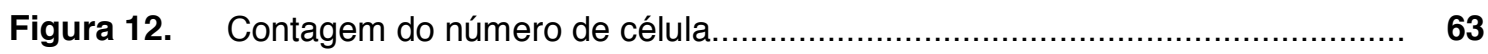

Figura 13. Atividade de fosfatase alcalina/proteína total........................................ 63

Figura 14. Determinação da área mineralizada $\left(\mathrm{mm}^{2}\right)$ em cultura de osteoblastos com chemerin

Figura 15. Determinação da expressão gênica de RANKL e OPG em cultura de osteoblastos

Figura 16. Determinação de área reabsorvida $\left(\mathrm{mm}^{2}\right)$ em cultura de células osteoclásticas com chemerin. 



\section{SUMÁRIO}

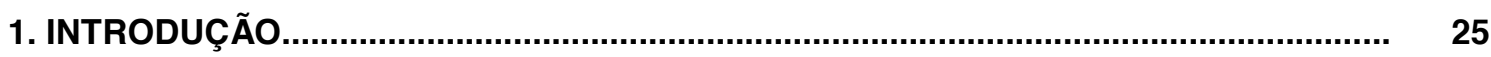

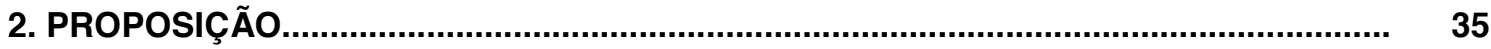

3. MATERIAIS E MÉTODOS........................................................................................ 39

4. RESULTADOS

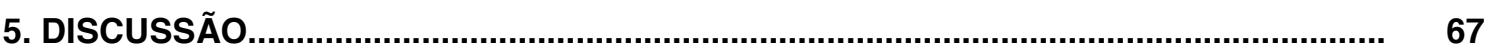

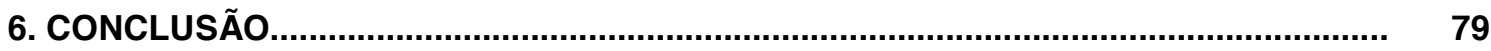

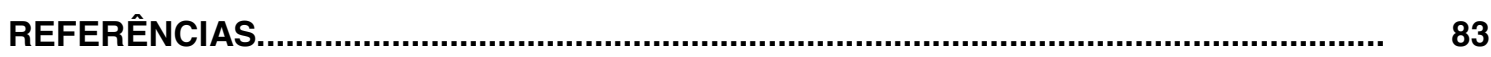

ANEXO 

INTRODUCÃ̃O 



\section{INTRODUÇÃO}

A doença periodontal (DP) é uma doença bucal infecto-inflamatória resultante da quebra da homeostase entre biofilme dentário e o hospedeiro (Page e Kornman, 1997) e que acomete os tecidos de suporte (gengiva) e sustentação (cemento, ligamento periodontal e osso) dos dentes (Brianezzi et al., 2013). De acordo com a organização mundial de saúde, a prevalência da doença periodontal grave na população mundial é de 10-15\% (Petersen e Ogawa, 2005). No Brasil, de acordo com a pesquisa nacional sobre a saúde bucal realizada pelo Ministério da Saúde, aproximadamente $30 \%$ da população adulta possui bolsas periodontais (Projeto SB Brasil, 2010). O estabelecimento e progressão desta doença envolvem um conjunto de fatores de risco locais, sistêmicos, ambientais e genéticos. Atualmente, são reconhecidos como fatores de risco para a doença periodontal a herança genética (Michalowicz et al., 2000), o fumo (Gelskey, 1999; Bergstrom et al., 2000; Ng e Leung, 2008a; Ebersole et al., 2014; Liu et al., 2014), o diabetes mellitus (Taylor et al., 1998; Borrel e Papananou, 2005), a obesidade e o sobrepeso (Zimmermann et al., 2013; Zhu et al., 2014), o estresse emocional ( $\mathrm{Ng}$ e Leung, 2008b), a depressão (Peruzzo et al., 2007) e o consumo de álcool (Tezal et al., 2004).

Dentre os indicadores de risco à periodontite, a obesidade e o sobrepeso tem despertado especial atenção. Por se tratarem de fatores de risco para uma série de outras doenças crônicas, configuram, atualmente, como importantes problemas de saúde pública (Genco et al., 2005; Pichon et al., 2007; Souza et al., 2010; Zimmermann et al., 2013; Zhu et al., 2014).

A obesidade e o sobrepeso são caracterizados por um acúmulo excessivo de gordura na forma de tecido adiposo, que apresenta riscos para a saúde (WHO, 2015). A classificação da obesidade é feita através do Índice de Massa Corporal (IMC), que é uma proporção entre o peso corpóreo dividido pelo quadrado da altura corporal, sendo considerado normal o IMC de 18,5 a 24,99 $\mathrm{Kg} / \mathrm{m}^{2}$, sobrepeso de 25 a $29,99 \mathrm{Kg} / \mathrm{m}^{2}$, obesidade grau I de 30 a $34,99 \mathrm{Kg} / \mathrm{m}^{2}$, obesidade grau II de 35 a $39,99 \mathrm{Kg} / \mathrm{m}^{2}$ e obesidade grau III ou obesidade mórbida $\geq$ $40 \mathrm{Kg} / \mathrm{m}^{2}$ (WHO, 2015). Considerando a incidência da obesidade entre os países desenvolvidos, na avaliação de 2011, os EUA apareciam em primeiro lugar, enquanto os japoneses eram os menos afetados pelo problema. O Brasil estava na 
$19^{\circ}$ posição no ranking mundial de obesidade masculino e na $15^{\circ}$ posição no ranking da obesidade feminina (Frederico, 2011). A incidência de obesidade duplicou no período entre 1980 e 2014 em todo o mundo. Em 2014, mais de 1,9 bilhões de adultos, com 18 anos ou mais, estavam acima do peso; destes, 600 milhões eram considerados obesos. Estes valores indicam que 39\% dos adultos, com 18 anos ou mais, estão acima do peso (38\% de homens e $40 \%$ das mulheres) e $13 \%$ são obesos (11\% homens e 15\% mulheres). Em 2013, 42 milhões de crianças com menos de 5 anos de idade estavam acima do peso ou obesas (WHO, 2015).

Uma das principais causas da obesidade e do sobrepeso é o desequilíbrio energético entre as calorias consumidas e as calorias gastas; no entanto, a etiologia da obesidade não é de fácil identificação uma vez que ela é considerada uma doença multifatorial, ou seja, é o resultado de uma complexa interação entre fatores comportamentais, genéticos, endócrinos, fisiológicos e psicológicos (Arçari et al., 2009).

Al-Zanhani et al. (2003), realizaram um estudo correlacionando a incidência e severidade de doença periodontal com o IMC. Neste estudo, os autores avaliaram 31.311 pacientes com idade entre 9 meses e 90 anos e detectaram que jovens apresentando IMC abaixo do considerado normal para suas idades, apresentaram $80 \%$ menos chance de desenvolver doença periodontal.

Perlstein e Bissada (1977) estudaram a influência da obesidade e/ou hipertensão na inflamação gengival e na resposta periodontal em animais. Após induzir um quadro de periodontite por 7 semanas em ratos, os autores puderam concluir que a obesidade contribuiu significativamente para a gravidade da periodontite. Os autores mostraram ainda, que a combinação de obesidade e hipertensão nos animais levaram a um quadro de doenças periodontais ainda mais agressivas.

Alguns anos mais tarde, Saito et al. (2001) concluiu, em um estudo longitudinal, que o aumento da gordura abdominal foi um fator chave na associação entre obesidade e doença periodontal. Os autores avaliaram a severidade da doença periodontal e correlacionaram com valores de IMC, relação cintura-quadril e gordura corporal, em 643 indivíduos. Dentre os indivíduos com o mesmo IMC (sobrepeso ou obeso) foi observado que a relação cintura-quadril ou medidas de gordura corporal foram determinantes para as diferentes profundidades de bolsa periodontal observadas. 
Um estudo recente avaliou se existe uma relação entre parâmetros antropométricos e a gravidade da doença periodontal. O estudo considerou, além do ganho de peso corporal, outros parâmetros como a circunferência da cintura e a área de gordura do braço. Nesta pesquisa os indivíduos selecionados (893 homens não diabéticos) foram acompanhados por até quatro décadas. A profundidade de bolsa ( $3 \mathrm{~mm}$ ) foi utilizada como parâmetro para mensurar a presença de doença periodontal. Os autores observaram que, os indivíduos que ganharam mais peso (> $0,19 \mathrm{Kg} / \mathrm{ano}$ ) apresentaram significantemente mais eventos de bolsa à sondagem do que os homens com menor ganho de peso ( $\leq 0,05 \mathrm{Kg} / \mathrm{ano})$. Mostrou ainda que, homens com excesso de peso no início do estudo e que apresentaram maior aumento da circunferência da cintura em um ano, tiveram mais bolsas periodontais que homens com menor aumento de circunferência da cintura. O aumento da gordura do braço foi associado com a progressão da doença periodontal em homens com peso normal. Estes resultados sugerem que alterações de adiposidade, e não apenas à alterações de peso em si, facilmente obtidas com medidas antropométricas podem ser considerados marcadores de risco da periodontite (Gorman et al., 2012).

\section{O Tecido Adiposo}

O tecido adiposo é um órgão metabolicamente ativo e essencial para o organismo. Este desempenha importantes funções fisiológicas, que contribuem para a homeostasia corporal. Este tecido representa cerca de $20 \%$ do peso corporal nos homens e 25 \% nas mulheres (Junqueira e Carneiro, 1999); e é constituído por adipócitos que compreendem 50\% e o restante é composto por tecido nervoso, fibras colágenas, nódulos linfáticos, leucócitos, macrófagos, células do mesênquima, fibroblastos e células precursoras dos adipócitos - os pré-adipócitos (FonsecaAlaniz et al., 2007; Cinti, 1999). Além de manter a homeostasia, diversas outras funções são atribuídas ao tecido adiposo, tais como o armazenamento de energia e as funções endócrina e imune (Farmer, 2009; Moulin et al., 2009; Wajchenberg et al., 2009; Guimarães et al., 2007).

Nos mamíferos, existem dois tipos de tecido adiposo: o tecido adiposo marrom e o tecido adiposo branco (Farmer, 2009; Fonseca-Alaniz et al., 2007; Pond, 2001). O tecido adiposo marrom é composto por adipócitos multiloculares com mitocôndrias abundantes e são responsáveis pela produção de calor e regulação da 
temperatura corporal (Dulloo et al., 2010). Este tecido é encontrado principalmente em recém-nascidos, na região em torno do ombro, apresentando elevada atividade metabólica (Fonseca-Alaniz et al., 2007). Em adultos, este tecido pode ser encontrado, em pequenas quantidades, próximo ao pescoço e na parte superior do tórax, apresentando-se metabolicamente ativo (Farmer, 2009). O tecido adiposo marrom recebe este nome por possuir elevada concentração de citocromo oxidase presente nas mitocôndrias (Fonseca-Alaniz et al., 2007).

O tecido adiposo branco é um tecido muito heterogêneo constituído por fibroblastos, pré-adipócitos, adipócitos maduros, macrófagos, vasos sanguíneos, nódulos linfáticos, células imunes e nervos (Ahima e Flier, 2000; Sanchez-Munoz et al., 2005; Ahima, 2006). Este tecido abrange as regiões subcutânea e visceral (Fonseca-Alaniz et al., 2007) e tem como função o armazenamento de gordura. Por sua distribuição bastante abrangente, oferece proteção mecânica contra choques e traumatismos externos, tem a capacidade de proporcionar um adequado deslizamento entre as vísceras e feixes musculares ao formar depósitos localizados em diversas regiões do organismo envolvendo orgãos e estruturas internas. Este tecido também participa da manutenção da temperatura corporal por ser um excelente isolante térmico e tem a capacidade de armazenar energia com necessidade de pouca água tornando-o um sistema tamponante importante para o balanço energético (Fonseca-Alaniz et al., 2006).

Além da classificação morfofuncional, o tecido adiposo pode ser denominado conforme a sua localização, como subcutâneo ou visceral. Segundo Fonseca-Alaniz et al. (2007) o tecido adiposo subcutâneo é aquele que possui depósitos de gordura situados abaixo da pele, nas regiões abdominal, glútea e femural; este tecido apresenta maior secreção de fatores anti-inflamatórios, tais como a adiponectina (Bastard et al., 2006). Por sua vez, o tecido adiposo visceral compreende o depósito de gordura encontrado próximo ou no interior dos órgãos da cavidade abdominal; este tecido desempenha importante papel na patogênese da doença cardiovascular, através da produção e secreção de mediadores pró-inflamatórios como TNF- $\alpha$ e interleucina-6 (IL-6) (Fonseca-Alaniz et al., 2007).

Os adipócitos sintetizam triglicérides (lipogênese) e oxidam ácidos graxos para obtenção de energia (lipólise) sem comprometimento de sua integridade funcional (Fonseca-Alaniz et al., 2007). De acordo com Bastard et al. (2006), os adipócitos apresentam propriedades semelhantes as células do sistema imune, com 
capacidade de produção de mediadores pró-inflamatórios, anti-inflamatórios e ativação do sistema complemento, além de desempenharem funções de fagocitose, semelhantemente aos macrófagos (Moulin et al., 2009; Bastard et al., 2006). Dados mais recentes têm mostrado que os adipócitos sintetizam e secretam proteínas metabolicamente ativas chamadas adipocinas (Shuldiner, Yang e Gong, 2001; Kougias et al., 2005; Fonseca-Alaniz et al., 2006; Yamawaki, 2011).

\section{Adipocina Chemerin}

As adipocinas são citocinas que atuam em diversos processos fisiológicos e fisiopatológicos. Existem mais de 50 adipocinas descritas, as quais desempenham funções autócrinas, parácrinas ou endócrinas, interferindo no metabolismo de lipídios e de glicose, contribuindo para o desenvolvimento de doenças cardiovasculares e processos inflamatórios. A produção de adipocinas pode ser regulada por estímulos inflamatórios e mediante condições de hipertrofia e/ou hiperplasia de adipócitos, encontrando-se alteradas em quadros de obesidade e síndrome metabólica (Guimarães et al., 2007; Bastard et al., 2006; Greenberg e Obin, 2006; Karmiris et al., 2006). As adipocinas liberadas pelo tecido adiposo também podem modular a diferenciação de osteoblastos e/ou adipócitos, e portanto, a função metabólica do osso (Gomez-Ambrosi et al., 2008). Tem sido relatado que as adipocinas leptina e a adiponectina são capazes de induzir a osteoblastogênese e o crescimento ósseo enquanto inibem a diferenciação de osteoclastos (Burguera et al., 2001; Oshima et al., 2005; Luo et al., 2005; Thomas et al., 1999; Yokota et al., 2002).

A adipocina chemerin é uma adipocina recentemente descoberta, é produzida em vários orgãos e tecidos, como o fígado, pulmão, rim e tecido adiposo (Bozaoglu et al., 2007; Roh et al., 2007). Esta adipocina é uma molécula também conhecido como tazaroteno, tem $18 \mathrm{Kd}$ e foi originalmente conhecida como um agente quimiotático para células do sistema imunológico, tais como macrófagos e células dendríticas (Wittamer et al., 2003). A pró-forma da proteína, a pró-chemerin, é produzida principalmente por adipócitos, fibroblastos, mastócitos e células endoteliais e circula no plasma como um precursor inativo. Uma vez secretado, a pró-chemerin pode ser ativada por serina proteases, como tripsina de mastócitos e elastase, produzidas por neutrófilos e mastócitos (Zabel et al., 2005), 
Os níveis de chemerin na circulação sanguínea estão relacionados com o IMC, concentração de triglicérides no plasma e pressão arterial (Bozaoglu et al., 2007). Ainda, a expressão de mRNA de chemerin foi descrita em adipócitos maduros e em tecido adiposo de animais obesos, sugerindo que a expressão dessa proteína pode refletir no estágio de diferenciação e tamanho do adipócito, bem como o total de massa adiposa (Bozaoglu et al., 2007). Os níveis de chemerin foram positivamente correlacionados com IMC, pressão arterial sistólica, níveis de triglicérides e de proteína $C$ reativa aumentados, em indivíduos com síndrome metabólica (Stejskal et al., 2008; Dong et al., 2011).

A adipocina chemerin ativa seletivamente um receptor da família das quimiocinas, o receptor CMKLR1 (chemokine-like receptor 1 ou ChemR23), um membro da família dos receptores acoplados à proteína G (Wittamer et al., 2004; Zabel et al., 2005; Bozaoglu et al., 2007; Roh et al., 2007; Takahashi et al., 2008; Kaur et al., 2010). O receptor para chemerin, CMKLR1 (ChemR23), é expresso por células endoteliais e sua expressão é regulada por citocinas pró-inflamatórias (TNF$\alpha$, IL-1 $\beta$ e IL-6), causando um aumento na angiogênese (Kaur et al., 2010).

Tem sido evidenciado que além de chemerin atuar em numerosos processos fisiológicos, como metabolismo, proliferação e diferenciação celular (Roman et al., 2012) esta adipocina está presente em células de tecidos inflamados, e sua capacidade em recrutar macrófagos sugerem a sua participação em processos inflamatórios (Wittamer et al., 2003; Zabel et al., 2005; Bozaoglu et al., 2007; Goralski et al., 2007; Parolini et al., 2007). Além disso, os níveis circulantes de chemerin estão aumentados em uma série de doenças, tais como colite ulcerativa e doença de Crohn (Weigert et al., 2010), doença hepática não-alcólica (Kukla et al., 2010), doença desmielinizante autoimmune (Graham et al., 2009) e lupus eritematoso (Gerl et al., 2010).

Estudos recentes mostraram que chemerin também regula a produção de citocinas inflamatórias e matriz metaloproteinases (MMPs) por condrócitos humanos in vitro. IL-1 $\beta$, TNF- $\alpha$, IL-6 e IL-8, bem como MMP-13 foram significantemente aumentados nos sobrenadantes de culturas de condrócitos estimulados com chemerin recombinate (Lannone and Lapadula, 2011).

As células da medula óssea são células pluripotentes que podem se diferenciar em várias linhagens como osteoblastos, adipócitos, condrócitos e miócitos. Em condições normais, quando o balanço entre a diferenciação 
adipogênica e osteoblastogênica favorece às células osteoblásticas, há a formação óssea. Entretando, em doenças como a osteoporose, esse balanço é interrompido, levando a adipogênese e diminuição da osteoblastogênese (Muruganan, Roman e Sinal, 2009; Quu et al., 2007). Vários fatores são reconhecidos como determinantes chaves na osteoblastogênese ou adipogênese. Como exemplo temos a vitamina $E$ e o estrogênio que são inibidores de adipogênese e promotores da osteoblastogênese in vitro e in vivo (Dang et al., 2002; Okazaki et al., 2002; Duque, Macoritto and Kremer, 2004).

As evidências mostrando que níveis séricos da adipocina chemerin estão aumentados em pacientes obesos, bem como aumento da expressão desta adipocina em células do tecido adiposo branco frente a estimulação com IL-1 $\beta$ in vitro, sugerem uma ligação funcional entre inflamação crônica e obesidade (Ernst et al., 2010; Ernst and Sinal, 2010).

Levando em consideração que alterações de adiposidade, observadas por medidas antropométricas, estão relacionadas com maior incidência de periodontite, e que chemerin, uma citocina produzida por adipócitos, está envolvida na resposta inflamatória, não existem dados na literatura que correlacionem o papel de chemerin na progressão da doença periodontal. Portanto, o presente projeto tem como objetivo avaliar o papel de chemerin na perda óssea induzida por periodontite em animais hiperlipidêmicos. 

Proposição 

2 ProposiçÃo

Este estudo tem como objetivos:

- Avaliar a possível correlação da adipocina Chemerin no desenvolvimento da doença periodontal em camundongos hiperlipidêmicos.

- Avaliar o efeito da adipocina Chemerin sobre a diferenciação e ativação de células ósseas. 

Materiale Métodos 



\section{Material e Métodos}

Este estudo foi aprovado pelo Comitê de Ética para o Uso de Animais em Pesquisa (CEUA) da Universidade de São Paulo / Campus de Ribeirão Preto, protocolo $\mathrm{n}^{\circ}$ 12.1.1783.53.3 (em anexo).

\subsection{Estudo da Adipocina Chemerin na Doença Periodontal em Camundongos Controle e Hiperlipidêmicos}

\section{Seleção dos animais}

Para o desenvolvimento da pesquisa foram utilizados 80 camundongos isogênicos machos da linhagem C57BL/6 (WT), recém-desmamados provenientes do biotério central do campus USP de Ribeirão Preto. Os animais foram mantidos durante todo o período experimental em mini-isoladoras, acondicionadas em ambiente com temperatura controlada de $22 \pm 2^{\circ} \mathrm{C}$ e ciclos de claro-escuro de $12 \mathrm{~h}$, com livre acesso à água e alimentação específica no biotério da Faculdade de Odontologia de Ribeirão Preto - USP.

\section{Distribuição dos animais nos grupos experimentais de acordo com a dieta}

Os animais recém desmamados (3 semanas) foram divididos, aleatoriamente, de acordo com a dieta. Os animais controle saudáveis receberam água à vontade e ração balanceada em pellets (3780 cal/Kg - Nuvilab®). Os animais hiperlipidêmicos receberam água à vontade e ração hiperlipídica integral rica em colesterol (34,5\%), com alto valor calórico em pellets (5254 cal/Kg - Pragsoluções $®)$. Os animais foram pesados semanalmente.

Tabela 1. Quadro comparativo de dieta

\begin{tabular}{c|cc}
\hline & $\begin{array}{c}\text { Dieta Controle } \\
\text { Nuvilab® }\end{array}$ & $\begin{array}{l}\text { Dieta Hiperlipídica } \\
\text { Pragsoluções }\end{array}$ \\
\hline Matéria mineral & $10,0 \%$ & $5 \%$ \\
Proteína bruta & $22,0 \%$ & $26 \%$ \\
Extrato eterio (gordura) & $4,0 \%$ & $34,5 \%$ \\
Fibra bruta & $5,73 \%$ & $8 \%$ \\
Carboidratos & $56 \%$ & $26,5 \%$ \\
Microelementos & $2,27 \%$ & - \\
Calorias & $3780 / \mathrm{kg}$ & $5205 / \mathrm{kg}$ \\
\hline
\end{tabular}




\section{Indução da doença periodontal}

O protocolo de indução da doença periodontal em camundongos foi realizado seguindo o modelo experimental descrito por Sasaki et al. (2004), com algumas modificações.

Inicialmente, quando os animais completaram 10 semanas, foi introduzido a antibioticoterapia com sulfametoxazol $(4 \mathrm{mg} / \mathrm{ml})$ e trimetoprima $(0,8 \mathrm{mg} / \mathrm{ml})$ na água ad libitum por um período de 4 dias para suprimir a microbiota selvagem da cavidade oral; seguido por mais 3 dias de água à vontade sem antibiótico. Os animais foram infectados com a inoculação oral de Porphyromonas gingivalis que foi cultivada em jarro de anaerobiose em meio ágar suplementado (TSBV). Uma vez colhidos da placa, os microrganismos foram transferidos para um tubo com PBS comparando-se com uma escala padrão de densidade bacteriana em meio líquido, foi determinada então a concentração de bactérias, em CFU. A solução foi diluída de modo a atingir a concentração de $10^{9} \mathrm{CFU}$ em $100 \mu \mathrm{L}$ de PBS. Os grupos de animais infectados foram submetidos ao protocolo que consiste da inoculação oral de $10^{9} \mathrm{CFU}$ em $100 \mu \mathrm{L}$ de PBS, acrescido de $2 \%$ de carboximetilcelulose. Esta solução foi aplicada diretamente na cavidade oral, próximo da região palatina dos incisivos centrais superiores dos animais com o auxílio de um micropipetador automático. Este procedimento de inoculação oral foi repetido 5 vezes em dias alternados (de 48 em $48 \mathrm{hs})$. Os animais controle foram submetidos à inoculação oral de $100 \mu \mathrm{L}$ de PBS acrescido de $2 \%$ de carboximetilcelulose (Prates et al., 2014). As amostras foram coletadas depois de 15, 30, 60 dias da inoculação inicial.

\section{Distribuição dos animais nos grupos experimentais de acordo com a doença periodontal}

Os animais controles ou submetidos à dieta hiperlipidêmica foram aleatoriamente distribuídos em 4 grupos, onde 2 grupos tiveram a indução da doença periodontal pela inoculação oral de Porphyromonas gingivalis (grupo Pg), e dois grupos submetidos à inoculação oral de PBS (grupo veículo) da seguinte forma:

- Grupo I: 20 camundongos controle não infectados (C+V)

- Grupo II: 20 camundongos controle infectados (C+Pg)

- Grupo III: 20 camundongos hiperlipidêmicos não infectados (H+V)

- Grupo IV: 20 camundongos hiperlipidêmicos infectados $(\mathrm{H}+\mathrm{Pg})$ 


\section{Quantificação dos parâmetros bioquímicos}

No final de cada período experimental, os animais foram anestesiados com cloridrato de quetamina (Ketamina 10\%, Agener União Química Farmacêutica Nacional S/A, Embu-Guaçu, SP) na dosagem de $150 \mathrm{mg} / \mathrm{Kg}$ de peso, e xilasina a $2 \%$ (Dopaser, Laboratórios Calier, SA, Barcelona, Espanha) na dosagem de 7,5 mg/Kg de peso, via intramuscular. A limpeza da pele foi feita com álcool $70 \%$, com o auxilio de uma tesoura cirúrgica foi feita a abertura da caixa torácia para se ter acesso ao coração e a coleta do sangue foi realizada por punção cardíaca com uma seringa contendo anticoagulante. As amostras foram acondicionadas em tubos plásticos tipo eppendorf ${ }^{\circledR}$. O plasma foi separado por processo de centrifugação a 2500rpm, 10 minutos, obtendo o plasma livre de hemólise (Zhou, 2004). Os parâmetros bioquímicos constaram das dosagens de colesterol total, triglicerídeos e glicose. Os ensaios foram realizados por sistema de identificação-espectrofotométrica com a utilização de kits comerciais Labtest®.

\section{Quantificação de Chemerin pelo Método Imuno-enzimático (ELISA)}

O plasma sanguíneo foi ainda utilizado para a quantificação da adipocina chemerin presente no sangue. A análise foi realizada pelo Método Imuno-enzimático (ELISA), utilizando-se pares de anticorpos de captura e detecção específicos para chemerin (R\&D Systems). Placas de 96 poços foram sensibilizadas com anticorpos monoclonais humanos (anticorpos de captura) para cada alvo. Após o bloqueio durante 1 hora a fim de evitar a ligação não específica, a proteína recombinante ou sobrenadantes de cultura foram adicionados. As citocinas foram detectadas após a ligação dos anticorpos de detecção (biotinilados) depois da ligação da enzima estreptavidina em cada poço. A reação colorimétrica resultante da adição do substrato foi parada pela adição de ácido sulfúrico $1 \mathrm{M}$, e as placas foram lidas a 450 $\mathrm{nm}$ por um leitor de microplacas. As concentrações de citocinas foram determinadas por interpolação de uma curva padrão e apresentadas como pg/mL ( \pm desvio padrão da média) para amostras em duplicata de cada uma das condições testadas.

\section{Análise do tecido adiposo retroperitoneal e epididimal}

Os tecidos adiposos retroperitoneal e epididimal foram coletados dos animais controle e hiperlipidêmicos depois de 60 dias de inoculação da Porphyromonas gingivalis para que fosse analisada a adiposidade corporal. Os 
tecidos adiposos foram removidos com o auxílio de uma tesoura cirúrgica, e pesados em balança digital calibrada. Os dados foram obtidos em gramas, tabulados e analisados.

\section{Quantificação gênica e protéica}

Extração, Isolamento e Avaliação do RNA total

O RNA total foi extraído do tecido gengival palatino ou de cultura de células. Após a incubação do homogenato durante 5 minutos em temperatura ambiente, foram adicionados $200 \mu \mathrm{L}$ de clorofórmio para cada $1 \mathrm{~mL}$ de Trizol. Os tubos foram agitados vigorosamente durante 15 segundos e incubados por 2 a 3 minutos em temperatura ambiente. As amostras foram centrifugadas a $12.000 \mathrm{~g}$ por 15 minutos, a $4^{\circ} \mathrm{C}$, com formação de duas fases. A fase aquosa (superior) foi transferida para outro tubo.

\section{Precipitação do RNA}

$\mathrm{Na}$ fase aquosa que foi transferida para um novo tubo foi acrescentado $500 \mu \mathrm{L}$ de isopropanolol. Os tubos foram misturados por imersão e incubados em $20^{\circ} \mathrm{C}$ por 20 minutos para precipitar o RNA da fase aquosa. Novamente, os tubos foram centrifugados a $12.000 \mathrm{~g}$ por 15 minutos, a $4^{\circ} \mathrm{C}$. O sobrenadante foi desprezado e adicionado ao precipitado $1 \mathrm{~mL}$ de etanol a $75 \%(\mathrm{v} / \mathrm{v})$ ao pellet. As amostras foram agitadas em vórtex e centrifugadas a $12.000 \mathrm{~g}$, por 5 minutos a $4^{\circ} \mathrm{C}$. O sobrenadante foi vertido e o pellet colocado à temperatura ambiente por 5-10 minutos. O RNAm foi ressuspendido em $10 \mu \mathrm{L}$ de água DEPC (dietilpirocarbonato).

\section{Quantificação do RNA}

A quantificação do RNA foi avaliada por espectrofotometria $(260 \mathrm{~nm})$ no aparelho NANODROP® (Thermo scientific, USA). O critério de pureza utilizado foi a razão 260/280 nm (ácido nucléico/proteína) de aproximadamente 1,8. Uma razão menor que 1,8 é indicativo de contaminação por proteínas. Foi utilizado um volume de $2 \mu \mathrm{L}$ para a leitura e a concentração da amostra foi fornecida em $\mathrm{ng} / \mu \mathrm{L}$.

\section{Reação de Transcriptase Reversa}

A reação de transcriptase reversa é o processo pelo qual o ácido ribonucléico (RNA) é usado como um molde para sintetizar ácido desoxirribonucléico 
complementar (cDNA). Para esta reação foi utilizado o Kit Multiscrib reverse transcription (Multiscrib RTß, Life Technologies).

PCR em tempo real (Polimerase em cadeia em tempo real - Real time)

A expressão dos genes foram quantificados pelo sistema TaqMan (Life Technologies). Este sistema utiliza sonda fluorescente para permitir a detecção de produto específico conforme este se acumula durante os ciclos de PCR. Uma sonda (oligonucleotídeo) foi construída contendo um corante sinalizador (reporter) fluorescente na extremidade 5' e um corante silenciador (quencher) na extremidade 3'. Enquanto a sonda está intacta, a proximidade do silenciador reduz bastante a fluorescência emitida pelo corante sinalizador através da transferência de energia por ressonância de fluorescência através do espaço. Se a sequência alvo estiver presente, a sonda se anela logo após um dos primers e é clivada pela atividade da nuclease 5' da Tag DNA polimerase enquanto o primer é estendido. Esta clivagem da sonda separa o corante sinalizador do corante silenciador, aumentando o sinal do primeiro, além de remover a fita alvo, permitindo a extensão do primer até o final da fita molde. As amostras foram analisadas no equipamento Step One Plus (Applied Biosystems). A reação em cadeia de polimerase (PCR) em tempo real foi realizada em um volume final de $13 \mu \mathrm{L}$ contendo oligonucleotídeos específicos, que serão construídos a partir de informações retiradas do GENEBANK.

Os genes de RANKL, OPG, catepsina K, chemerin e o receptor CMKLR-1 foram analisados. Um valor de limiar (threshold) para cada gene foi fixado. $O$ threshold é um nível de sinal do corante sinalizador normalizado utilizado para determinação do Ct (ciclo threshold) em ensaios de tempo real. Ele deve ser ajustado acima do sinal fluorescente de fundo emitido durante os primeiros ciclos antes de detectar a amplificação do produto (baseline). O Ct é o número do ciclo no qual a fluorescência gerada dentro de uma reação cruza a linha threshold. Os valores de Ct são logarítimos e são usados para as análises quantitativas. A expressão gênica foi analisada pelo método de $2^{\Delta \mathrm{Ct}}$. A média de Ct e o desvio padrão das triplicatas foram calculados. Os valores de $2^{\Delta \mathrm{Ct}}$ de cada amostra foi normalizado ( $\log 10)$ e os grupos foram comparados. 


\subsection{Estudo Morfométrico da Reabsorção Óssea}

O estudo morfométrico da reabsorção óssea foi feito de acordo com o trabalho de Verzeletti e colaboradores (2011).

\section{Manipulação da amostra}

As maxilas foram dissecadas manualmente e então imersas em solução de hipoclorito de sódio a 5\% (Mazzarollo, Gravataí, RS, Brasil) durante 5 hs para remover todo o tecido. Depois de serem enxaguadas, as amostras foram coradas durante $1 \mathrm{~min}$. em azul de metileno a 1\% (Sigma-Aldrich, Saint Louis, MO, EUA) para a junção amelocementária ser detectada. A perda óssea alveolar foi medida da junção amelocementaria à crista óssea alveolar. As imagens foram padronizadas e tiradas de cada espécime, juntamente com uma régua por uma câmera fotográfica digital com lentes médias e aumento de 2,5x (Canon EOS 1000D), acoplada a uma lupa de dissecção (Zeiss CL 1500 ECO). As fotos foram tiradas da face bucal e palatina do espécime. As medidas foram mensuradas pelo programa computadorizado de análise de imagem (Image J). Cinco medições foram feitas por imagem e a média destas foi considerada. Todas as mensurações foram feitas às cegas por um examinador.

\subsection{Estudo em Cultura Primária de Células Osteoblásticas - Avaliação da Viabilidade Celular, Conteúdo de Proteína Total, Atividade da Fosfatase Alcalina e Formações Nodulares de Matriz Mineralizada}

\section{Seleção dos animais}

Para a realização do estudo em cultura primária de células osteoblásticas foi necessário de 10 a 15 camundongos de 3-4 semanas de vida pós-natal para cada cultura; os animais foram provenientes do Biotério Central da Universidade de São Paulo - Campus Ribeirão Preto.

\section{Cultura de células osteoblásticas}

A diferenciação de osteoblastos murinos foi realizada a partir de cultura primária utilizando células da medula óssea. Para isso, o fêmur e a tíbia de camundongos foram assepticamente removidos com o auxílio de uma tesoura cirúrgica pequena, e as medulas ósseas extraídas utilizando meio de cultura Meio Essencial Mínimo, modificação alfa, ( $\alpha-M E M$, Gibco, Invitrogen), suplementado com 
soro fetal bovino 10\% (Gibco, Invitrogen) e com $50 \mu \mathrm{g} / \mathrm{ml}$ de gentamicina (Gibco, Invitrogen), $2 \mathrm{mM}$ de L-glutamina. As células foram cultivadas em meio de diferenciação de osteoblastos, contendo ácido ascórbico $(50 \mu \mathrm{g} / \mathrm{ml}), \beta$-glicerofosfato $(10 \mathrm{mM})$ e dexametasona $(10 \mathrm{nM})$. Após período necessário para a expansão celular, estas foram contadas na câmara de Neubauer e plaqueadas sobre as superfícies de Thermanox ${ }^{\circledR}$ na densidade de $2 \times 10^{4}$ células/poço, em placas de poloestireno de 24 poços. As células plaqueadas foram novamente cultivadas em meio de diferenciação por períodos de até 14 dias em temperatura de $37^{\circ} \mathrm{C}$ em atmosfera úmida contendo $5 \%$ de $\mathrm{CO}_{2}$. O meio de cultura foi retirado dos poços e o novo meio de cultura contendo a adipocina Chemerin foi adicionado 72 horas após o plaqueamento: Grupo I: meio de cultura sem adição de nenhum material. Grupo II: meio de cultura contendo a adipocina Chemerin. O meio de cultura foi trocado a cada três dias e a progressão da cultura avaliada por microscopia de fase. Todos os experimentos descritos foram feitos em quintuplicata $(n=5)$. Inicialmente foi feito um experimento piloto para se observar as curvas de concentração-efeito e determinar a concentração de Chemerin para a cultura de osteoblastos. Foram utilizadas as concentrações de 1,10 e $100 \mathrm{ng} / \mathrm{mL}$ de chemerin. A contagem, proliferação e atividade celular foram observadas.

\section{Avaliação da contagem de células}

A contagem das células foi realizada com 7 dias. Para isso, a cultura foi lavada $2 x$ com PBS seguido pela desaderência e separação das células com tripsina. Estas células foram coradas com azul de tripan 1\% (Sigma $\left.{ }^{\circledR}\right)$ e contadas em câmara de Neubauer ao microscópio ótico.

\section{Conteúdo de proteína total}

A concentração da proteína celular total foi quantificada através do método colorimétrico de um kit comercial (BCA protein Thermo Scientific ${ }^{\circledR}$ ). Inicialmente, o meio de cultura dos poços foi removido, os poços foram lavados três vezes com salina tamponada com fosfato e preenchidos com $2 \mathrm{~mL}$ de solução de laurilsulfato de sódio $0,1 \%$ (Sigma). Na placa de 96 poços foram colocados $5 \mu \mathrm{l}$ da amostra preparada com laurilsulfato de sódio $0,1 \%$ e $200 \mu \mathrm{l}$ da solução preparada previamente com a mistura do composto A e composto B na proporção de 50:1, respectivamente. Seguido pela incubação por 30 minutos na estufa à temperatura média de $37^{\circ}$. Em seguida, a densidade óptica foi lida em comprimento de onda de $562 \mathrm{~nm}$ em espectrofotômetro e os dados expressos como absorbância ( $\mu \mathrm{g} / \mathrm{mL})$. 


\section{Atividade de fosfatase alcalina}

A atividade de fosfatase alcalina foi medida aos 7 e 14 dias através da liberação de timolftaleína pela hidrólise do substrato de timolftaleína monofosfato, utilizando um kit comercial (Labtest ${ }^{\circledR}, \mathrm{BH}, \mathrm{MG}$, Brasil). Tubos de ensaio foram utilizados para receberem a amostra padrão, branco e amostras testes. Em todos os tubos foram adicionado $50 \mu \mathrm{l}$ de substrato e $500 \mu \mathrm{l}$ de tampão. No tubo padrão foi acrescentado $50 \mu \mathrm{l}$ da solução padrão. Os tubos foram mantidos em banho-maria a $37^{\circ} \mathrm{C}$ por 2 minutos. Em seguida, foi adicionado, em cada tubo teste $50 \mu \mathrm{l}$ da suspensão com laurel sulfato de sódio dos mesmos poços utilizados para a medida da proteína total. Os tubos foram mantidos em banho-maria a $37^{\circ} \mathrm{C}$ por 10 minutos. Após esse período foi adicionado em cada tubo, branco, padrão e testes, $2 \mathrm{ml}$ do reagente de cor. Alíquotas de $150 \mu \mathrm{l}$ da solução de cada poço foram transferidas para placas de 96 poços para posterior quantificação. A densidade óptica foi lida em comprimento de onda de $590 \mathrm{~nm}$ em espectrofotômetro e os dados expressos como absorbância. A atividade de fosfatase alcalina, expressa em $\mu \mathrm{mol}$ de timolftaleína/h/mg, foi calculada a partir da medida do tubo padrão e normalizada pela quantidade de proteína total.

\section{Formações nodulares de matriz mineralizada}

A mineralização foi analisada através da marcação dos depósitos de cálcio coradas pelo vermelho de Alizarina $\left(\right.$ Sigma $\left.^{\circledR}\right)$ na cultura de células osteoblásticas com 21 dias. Inicialmente o meio de cultura foi removido, os poços lavados três vezes com PBS e preenchidos com paraformaldeído a $4 \%$ por 30 dias. Em seguida, os poços foram desidratados por uma hora em série crescente de álcoois $(30 \%$, $50 \%, 70 \%, 100 \%$ ) e as culturas processadas para a coloração com vermelho de Alizarina (Sigma, St. Louis, MO, EUA); e, as amostras foram observadas por microscopia de fluorescência (Axio Imager, Zeiss, Jena, Alemanha) acoplado a uma câmara fotográfica digital (AxioCam MRm, Zeiss, Jena, Alemanha). As imagens foram analisadas usando o software Image Tool (Universidade of Texas Health Sciences Center, San Antonio, TX, USA), de acordo com Rosa e Beloti (2003), com as imagens submetidas à transformação binária. Os resultados foram obtidos através de uma descrição qualitativa de imagens representativas de cada grupo. 


\subsection{Estudo em Cultura Primária de Células Osteoclásticas - Ensaio de Reabsorção Óssea}

A diferenciação de osteoclastos murinos foi realizada a partir de cultura primária utilizando células da medula óssea. Para isso, o fêmur e a tíbia de camundongos foram assepticamente removidos com o auxílio de uma tesoura cirúrgica pequena e as medulas ósseas extraídas. As células foram cultivadas em meio de cultura a-MEM (Gibco, Invitrogen), suplementado com soro fetal bovino $10 \%$ por 3 dias em presença de MCSF (30ng/ml). Para os ensaios de reabsorção 20.000 foram plaqueadas em placas de osteoassay (Corning) na presença de MCSF (30ng/ml), RANKL $(5 \mathrm{ng} / \mathrm{ml})$ e chemerin $(1-100 \mathrm{ng} / \mathrm{ml})$ de acordo com cada grupo experimental. Depois de 7 dias, as células semeadas sobre os poços calcificados foram removidas pela adição do hipoclorito de sódio 5\% (Sigma-Aldrich, EUA), em seguida foram coradas com azul de toluidina $0,1 \%$ (Sigma-Aldrich, EUA). A área de reabsorção foi avaliada utilizando um microscópio óptico com câmara acoplada (Leica, Alemanha).

\subsection{Análise Estatística}

Os dados numéricos foram analisados por meio do programa estatístico Graph Pad Prism 5 (Graph Pad Software In., San Diego, Califórnia, EUA). Os resultados foram expressos como média \pm erro padrão da média (EPM). A análise dos resultados foi realizada pelo método de variância de uma via (One-way ANOVA), seguido de post teste de Tukey, sendo o nível de significância adotado de $5 \%(p<0,05)$. 

Resultados 



\section{Resultados}

\subsection{Peso Corpóreo dos Animais}

O modelo de dieta hipercalórica estabelecido neste estudo adotou uma ração hiperlipídica contendo $34,5 \%$ de gordura. Os animais foram monitorados semanalmente em relação ao peso corpóreo até o final das coletas. Tanto o grupo controle quanto o grupo hiperlipidêmico, infectados ou não, apresentaram aumento do peso durante o período em que foram acompanhados. Não houve diferença estatística entre o peso dos animais nos diferentes grupos. Os dados mostram ainda que a infecção com Porphyromonas gingivalis não comprometeu o ganho de peso desses animais (Figura 1).

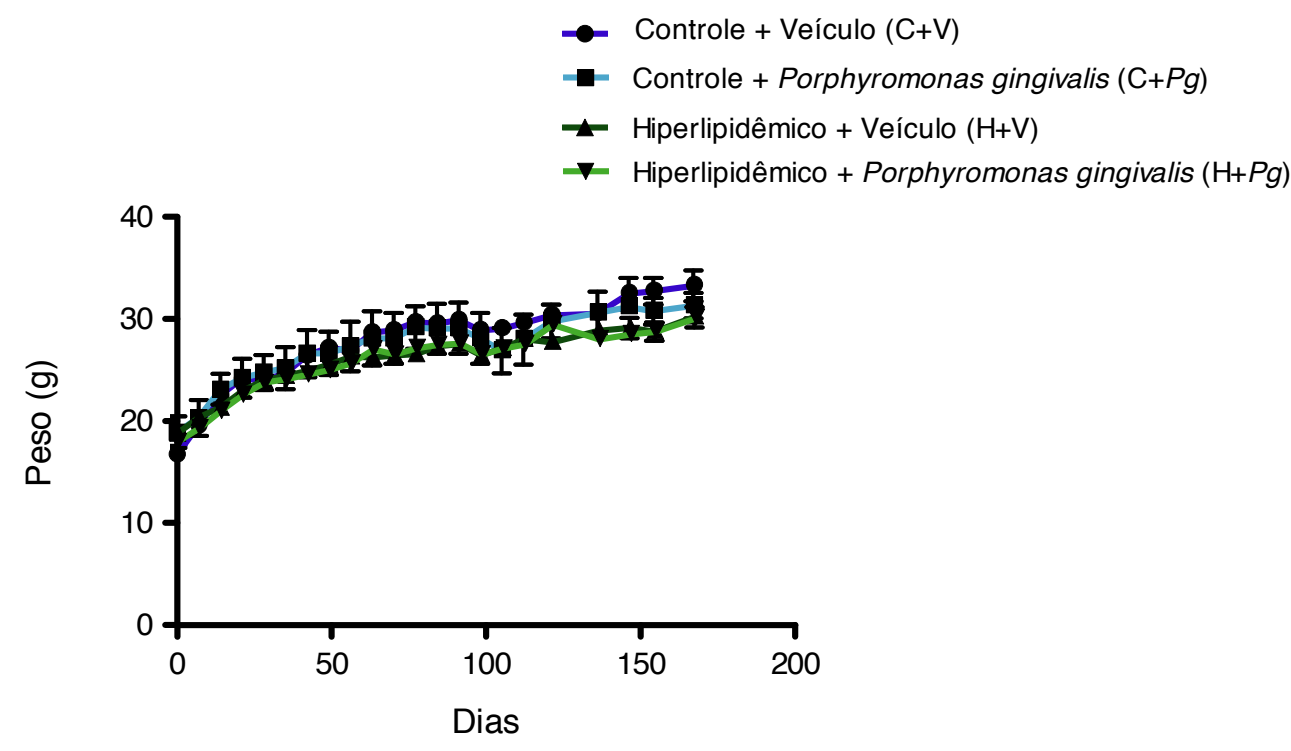

Figura 1. Avaliação do peso corpóreo dos animais durante o período experimental: $O$ peso dos animais foi aferido a cada 7 dias, durante todo o período experimental (0-167 dias).

\subsection{Análise do Tecido Adiposo Retroperitoneal e Epididimal}

A adiposidade corporal é um importante fator de risco para diversas doenças; no entanto, é o tecido adiposo visceral que apresenta maior correlação com o desenvolvimento de alterações metabólicas (Ribeiro-Filho, 2006). Em roedores, a gordura visceral é composta principalmente pelos depósitos epididimal e retroperitoneal (Mauer, Harris and Bartness, 2001); por isso, estes tecidos foram coletados após 60 dias de inoculação bacteriana e o peso tecidual dos diferentes grupos foi comparado. 

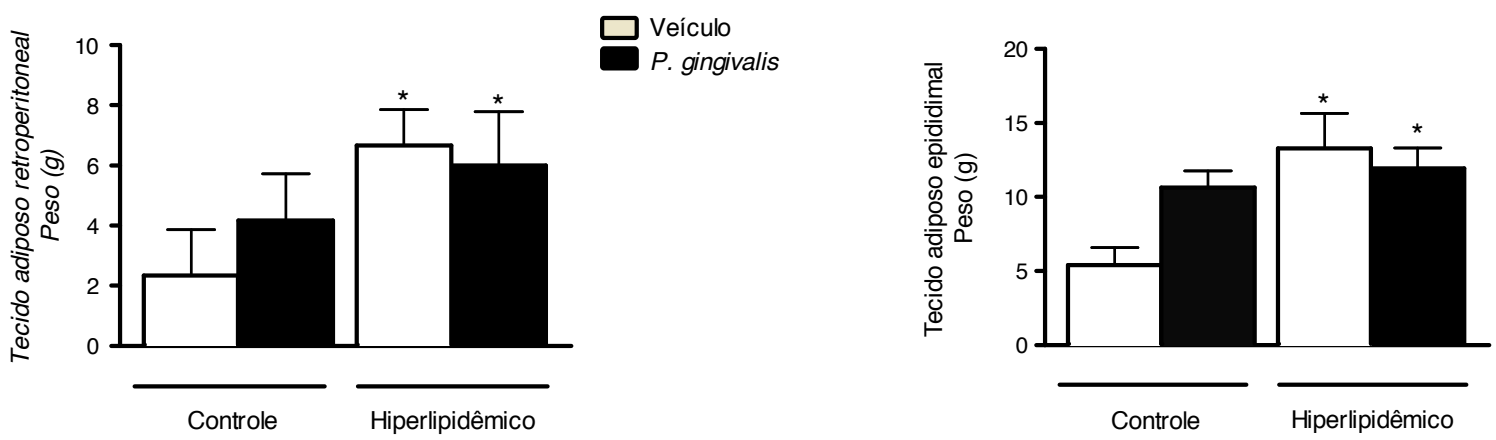

Figura 2. Peso dos tecidos adiposos retroperitoneal e epididimal nos diferentes grupos experimentais: Os tecidos adiposos retroperitoneal e epididimal foram coletados dos animais controle e hiperlipidêmicos depois de 60 dias de inoculação bacteriana pela $P$. gingivalis e pesados. Os valores indicam a média do peso em $\mathrm{g} \pm \mathrm{EPM}$. * $\mathrm{p}<0,05$ em relação ao grupo controle+veiculo.

Os resultados mostraram que o peso do tecido adiposo retroperitoneal e do tecido adiposo epididimal aumentaram nos grupos tratados com dieta hiperlipidêmica quando comparados ao grupo controle. $O$ tecido adiposo retroperitoneal dos animais controle pesaram 2,3 $\pm 0,7 \mathrm{~g}$ enquanto no grupo hiperlipidêmico pesaram 6,6 $\pm 0,7 \mathrm{~g}$. Em relação ao tecido adiposo epididimal, foi observado um aumento de peso que foi de 5,4 $\pm 1,1 \mathrm{~g}$ (grupo controle) para 13,3 \pm 2,4 g no grupo hiperlipidêmico. Não observamos diferença estatisticamente significativa no peso dos tecidos adiposo retroperitoneal ou epididimal após infecção com a $P$. gingivalis.

\subsection{Parâmetros Bioquímicos}

Com o objetivo de avaliar se a dieta hiperlipidêmica alterou parâmetros bioquímicos como colesterol total, triglicérides e glicemia plasmática, estes foram determinados nos diferentes períodos experimentais $(15,30$ e 60 dias após inoculação bacteriana).

Os resultados da tabela 2 mostraram que, após 15 dias de inoculação bacteriana, os animais hiperlipidêmicos apresentaram uma maior concentração de colesterol no plasma sanguíneo quando comparado aos animais controle ( $p<0,0001)$. A concentração glicêmica do grupo $\mathrm{H}+\mathrm{Pg}$ foi maior em relação ao grupo $\mathrm{C}+\mathrm{V}(\mathrm{p}<0,05)$ e ao grupo $\mathrm{C}+\mathrm{Pg}(\mathrm{p}<0,0001)$. A concentração de triglicérides foi semelhante entre os grupos. 
Tabela 2. Concentração plasmática de colesterol total, triglicérides e glicose (15 dias)

\begin{tabular}{ccccc}
\hline & CONTROLE & \multicolumn{3}{c}{ HIPERLIPIDËMICO } \\
\hline & Veículo & P.gingivalis & Veículo & P.gingivalis \\
Colesterol & $83,4 \pm 4$ & $66,3 \pm 3$ & $130,8 \pm 6^{* * *}$ & $115,2 \pm 4^{\star * *}$ \\
Triglicérides & $57,3 \pm 4$ & $55,4 \pm 6$ & $49,3 \pm 8$ & $71,7 \pm 4$ \\
Glicose & $213,4 \pm 16$ & $155,9 \pm 17$ & $221,2 \pm 12$ & $299,8 \pm 20^{\#+}$ \\
\hline
\end{tabular}

Concentração $(\mathrm{mg} / \mathrm{dL})$ de colesterol total, triglicérides e glicose no plasma sanguíneo dos animais controle e hiperlipidêmicos depois de 15 dias de inoculação bacteriana pela $P$. gingivalis ${ }^{* \star *} p<0,0001$ em relação aos grupos $\mathrm{C}+\mathrm{V}$ e $\mathrm{C}+\mathrm{Pg}$; ${ }^{\#} \mathrm{p}<0,05$ em relação ao grupo $\mathrm{C}+\mathrm{V}$ e em relação ao grupo $\mathrm{H}+\mathrm{V}$; ${ }^{+} \mathrm{p}<0,0001$ em relação ao grupo $\mathrm{C}+\mathrm{Pg}$.

A tabela 3 mostrou que, após 30 dias de inoculação bacteriana, os animais hiperlipidêmicos apresentaram uma maior concentração de colesterol no plasma sanguíneo quando comparado aos animais controle $(p<0,0001)$. A concentração glicêmica do grupo $\mathrm{H}+\mathrm{Pg}$ foi maior em relação ao grupo $\mathrm{C}+\mathrm{Pg}(\mathrm{p}<0,05)$. $\mathrm{A}$ concentração de triglicérides foi semelhante entre os grupos.

Tabela 3. Concentração plasmática de colesterol total, triglicérides e glicose (30 dias)

\begin{tabular}{ccccc}
\hline & CONTROLE & & HIPERLIPIDËMICO & P.gingivalis \\
\hline & Veículo & P.gingivalis & Veículo & $106,0 \pm 6^{\star \star *}$ \\
Colesterol & $64,6 \pm 3$ & $65,0 \pm 4$ & $103,0 \pm 6^{\star \star *}$ & $40,0 \pm 4$ \\
Triglicérides & $66,1 \pm 11$ & $64,3 \pm 8$ & $44,7 \pm 6$ & $225,9 \pm 7^{*}$ \\
\hline
\end{tabular}

Concentração de colesterol total, triglicérides e glicose no plasma sanguíneo dos animais controle e hiperlipidêmicos depois de 30 dias de inoculação bacteriana pela $P$. gingivalis ${ }^{\star \star *} \mathrm{p}<0,0001$ em relação aos grupos $\mathrm{C}+\mathrm{V}$ e $\mathrm{C}+\mathrm{Pg}$; ${ }^{*} \mathrm{p}<0,05$ em relação ao grupo $\mathrm{C}+\mathrm{Pg}$.

A tabela 4 mostrou que, após 60 dias de inoculação bacteriana, os animais hiperlipidêmicos apresentaram uma maior concentração de colesterol no plasma sanguíneo quando comparado aos animais controle $(p<0,0001)$. A concentração de triglicérides foi menor no grupo $\mathrm{H}+\mathrm{Pg}$ quando comparado aos grupos $\mathrm{C}+\mathrm{V}$ e $\mathrm{H}+\mathrm{V}$ $(p<0,01)$. A concentração glicêmica foi semelhante entre os grupos. 
Tabela 4. Concentração plasmática de colesterol total, triglicérides e glicose (60 dias)

\begin{tabular}{ccccc}
\hline & CONTROLE & & HIPERLIPIDËMICO & \\
\hline & Veículo & $P$. gingivalis & Veículo & $P$. gingivalis \\
Colesterol & $86,5 \pm 5$ & $80,3 \pm 3$ & $118,6 \pm 5^{\star \star *}$ & $125,7 \pm 7^{\star \star \star}$ \\
Triglicérides & $69,2 \pm 9$ & $55,6 \pm 4$ & $79,5 \pm 8$ & $31,3 \pm 2^{\star *}$ \\
Glicose & $213,8 \pm 23$ & $297,9 \pm 29$ & $263,1 \pm 25$ & $236,7 \pm 19$ \\
\hline
\end{tabular}

Concentração de colesterol total, triglicérides e glicose no plasma sanguíneo dos animais controle e hiperlipidêmicos depois de 60 dias de inoculação bacteriana pela $P$. gingivalis ${ }^{* \star *} \mathrm{p}<0,0001$ em relação aos grupos $\mathrm{C}+\mathrm{V}$ e $\mathrm{C}+\mathrm{Pg} ;{ }^{* *} \mathrm{p}<0,01$ em relação ao grupo $\mathrm{C}+\mathrm{V}$ e ao grupo $\mathrm{H}+\mathrm{V}$.

\subsection{Fotografia Representativa da Reabsorção Óssea Alveolar}

Para análise da extensão da reabsorção óssea alveolar foi considerada a soma da área entre a junção cemento-esmalte (JCE) e a crista óssea alveolar (COA) dos primeiros e segundos molares de cada grupo experimental. A ilustração abaixo é uma foto representativa das maxilas removidas após 60 dias de infecção com $P$. gingivalis e mostram a área de perda óssea alveolar que foram quantificadas e os valores utilizados para a construção dos gráficos a seguir.

VEÍCULO
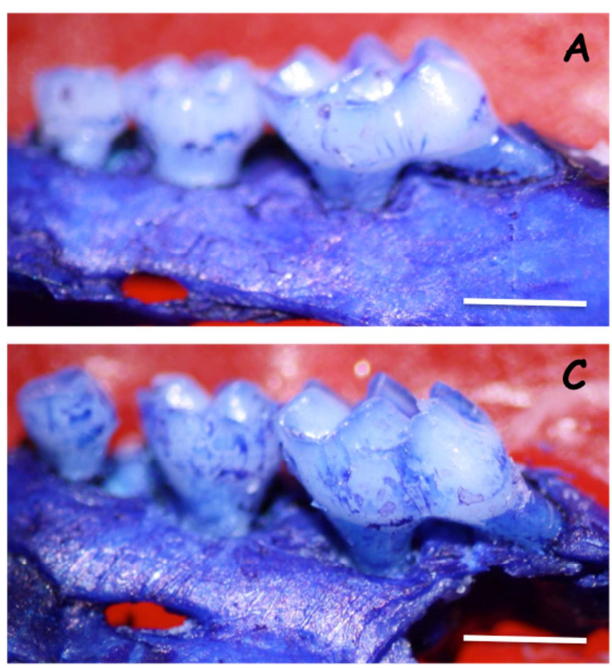

PORPHYROMONAS GINGIVALIS

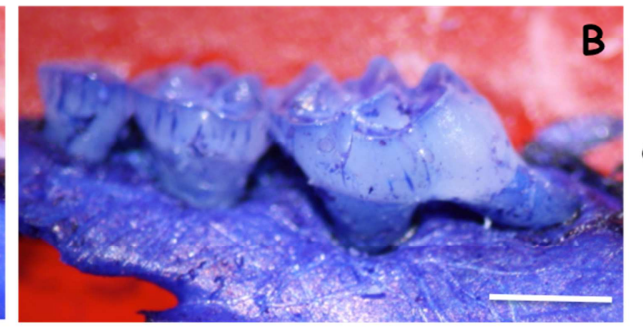

CONTROLE

D

HIPERLIPIDÊMICO

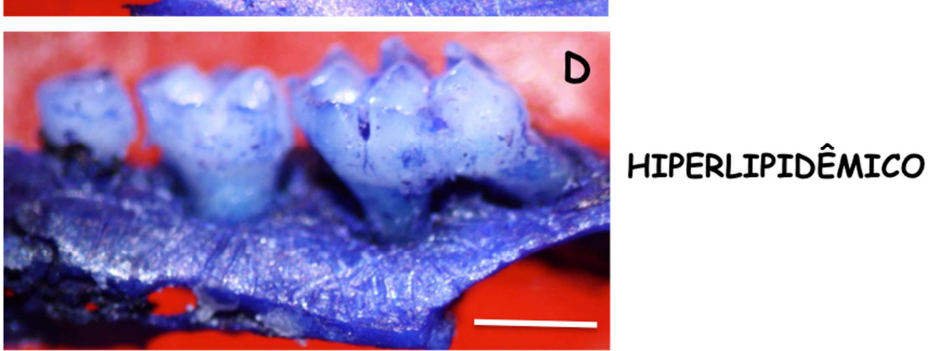

Figura 3. Foto representativa da reabsorção óssea alveolar depois de 60 dias de infecção: Fotos representativas da reabsorção óssea alveolar da face palatina das hemi-maxilas dos animais do grupo $\mathrm{C}+\mathrm{V}(\mathrm{A}), \mathrm{C}+\mathrm{Pg}(\mathrm{B}), \mathrm{H}+\mathrm{V}(\mathrm{C})$ e $\mathrm{H}+\mathrm{Pg}(\mathrm{D})$ depois de 60 dias de infecção pela $P$. gingivalis. As peças foram fotografadas com aumento de 2,5x e a barra equilave a $1 \mathrm{~mm}$.

\subsection{Estudo Morfométrico da Reabsorção Óssea induzida pela Periodontite em Maxilas de Camundongos Controle e Hiperlipidêmico}

A extensão da reabsorção óssea alveolar foi analisada em diferentes tempos após a inoculação bacteriana. Ao analisar a área de reabsorção dos animais após 
15 dias de infecção, notamos que a inoculação bacteriana ou a dieta não foram capazes de alterar a perda óssea. Neste período avaliado, embora não tenha sido estatisticamente significante, foi observado que os grupos $\mathrm{C}+\mathrm{Pg}, \mathrm{H}+\mathrm{V}$ e $\mathrm{H}+\mathrm{Pg}$ apresentaram maiores áreas de reabsorção óssea quando comparado ao grupo $\mathrm{C}+\mathrm{V}$. Por outro lado, após 30 dias de infecção, demonstrou-se um aumento estatisticamente significante na reabsorção óssea nos grupos $\mathrm{C}+\mathrm{Pg}, \mathrm{H}+\mathrm{V}, \mathrm{H}+\mathrm{Pg}$ quando comparado ao grupo controle $(\mathrm{C}+\mathrm{V})$. A área de reabsorção óssea entre os grupos $\mathrm{C}+\mathrm{Pg}, \mathrm{H}+\mathrm{V}$ e $\mathrm{H}+\mathrm{Pg}$ foram semelhantementes altos. No período de 60 dias de infecção, foi observado uma maior área de reabsorção óssea nos grupos hiperlipidêmicos, com diferença estatística, comparado ao grupo $\mathrm{C}+\mathrm{V}(\mathrm{P}<0,05)$. $\mathrm{O}$ grupo $\mathrm{H}+\mathrm{V}$, assim como nos outros dois períodos experimentais, apresentaram $\mathrm{o}$ mesmo padrão de reabsorção óssea que o grupo $\mathrm{H}+\mathrm{Pg}$, mesmo não sendo infectado pela $P$. gingivalis.
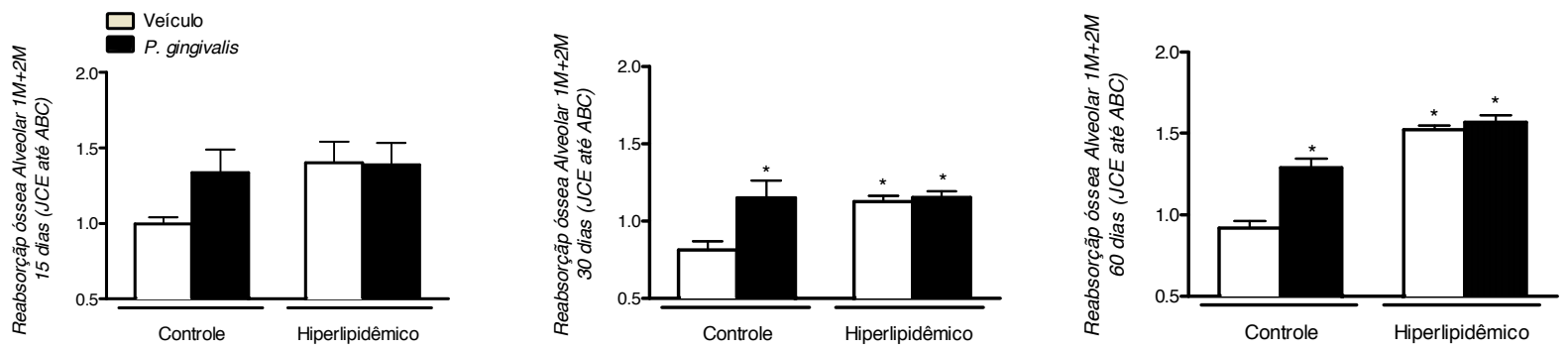

Figura 4. Análise macroscópica da reabsorção óssea alveolar maxilar: Reabsorção óssea alveolar maxilar observada em animais controle e hiperlipidêmico, infectados ou não pela $P$. gingivalis. A extensão da reabsorção óssea alveolar foi verificada pela soma da área entre a junção cemento-esmalte (JCE) e a crista óssea alveolar (COA) dos primeiros e segundos molares superiores de cada grupo experimental. ${ }^{*} \mathrm{P}<0,05$ comparado ao grupos $\mathrm{C}+\mathrm{V}$.

\subsection{Avaliação da Expressão Gênica de Chemerin e o Receptor CMKLR-1 em Gengiva de Animais Controle e Hiperlipidêmico Infectados ou não por $\boldsymbol{P}$. gingivalis}

Com o objetivo de estudar o papel de chemerin na perda óssea induzida por periodontite, inicialmente avaliamos se chemerin e seu receptor CMKLR-1 estavam expressos no tecido gengival dos animais controle e hiperlipidêmicos infectados por $P$. gingivalis. A expressão gênica por qPCR foi analisada em amostras de tecido gengival palatal desses animais em todos os períodos experimentais $(15,30$ e 60 dias). 

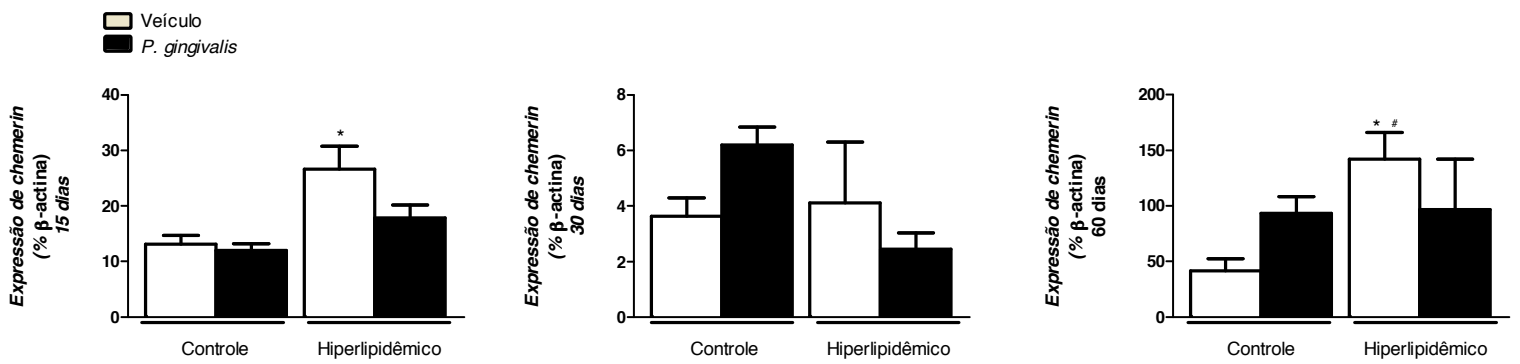

Figura 5. Determinação da expressão gênica da adipocina chemerin: Avaliação da expressão gênica de chemerin por qPCR em amostras de tecido gengival palatal de animais controle e hiperlipidêmicos, infectados ou não por $P$. gingivalis. $O$ resultado do gene alvo está expresso em relação à \% da expressão do gene endógeno $\beta$-actina ${ }^{*} \mathrm{p}<0,05$ em relação aos grupos $\mathrm{C}+\mathrm{V}$ e $\mathrm{C}+\mathrm{Pg}$. \# $\mathrm{p}<0,05$ em relação ao grupo $\mathrm{H}+\mathrm{Pg}$.

Nos primeiros 15 dias após a inoculação bacteriana, observou-se uma maior expressão de chemerin no grupo $\mathrm{H}+\mathrm{V}$ com diferença estatisticamente significante $(p<0,05)$ quando comparado aos grupos $\mathrm{C}+\mathrm{V}$ e $\mathrm{C}+\mathrm{Pg}$. Aos 30 dias de infecção, foi observado uma semelhança na expressão de chemerin entre os grupos experimentais, mas ressalta-se que a expressão da adipocina chemerin diminuiu em relação ao primeiro período experimental (15 dias). No terceiro período experimental, depois de 60 dias de inoculação bacteriana, houve um pico de expressão de chemerin no grupo $\mathrm{H}+\mathrm{V}$, com diferença estatisticamente significante, quando comparado aos grupos $\mathrm{C}+\mathrm{V}$ e $\mathrm{H}+\mathrm{Pg}(\mathrm{p}<0,05)$.

Foi observada a presença do receptor de chemerin CMKLR-1 no tecido gengival dos camundongos controle e hiperlipidêmicos utilizados neste estudo. Depois de 15 dias de inoculação bacteriana, não houve diferença estatística na expressão do receptor CMKLR-1 entre os grupos testados; os grupos controle e hiperlipidêmicos não infectados tiveram maior expressão do receptor embora a diferença não seja estatisticamente diferente. Nos animais com 30 dias de infecção, não foi observada diferença na expressão do receptor CMKLR-1 entre os grupos. Com 60 dias de infecção, o grupo $\mathrm{H}+\mathrm{V}$ apresentou maior expressão de receptor CMKLR-1, diferença estatisticamente significante quando comparado ao grupo controle $(\mathrm{C}+\mathrm{V})(\mathrm{p}<0,05)$. 

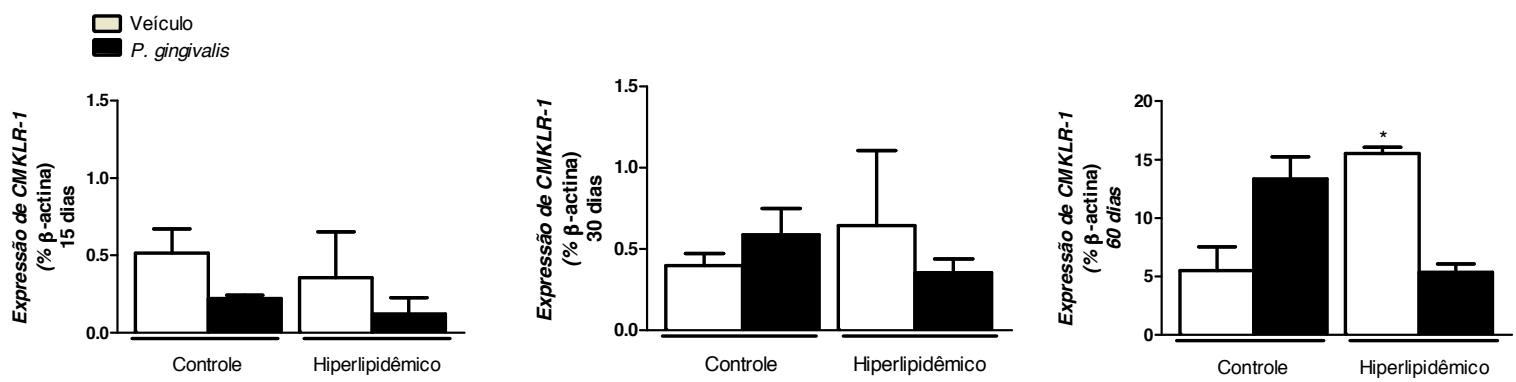

Figura 6. Determinação da expressão gênica do receptor de chemerin - CMKLR-1: Avaliação da expressão gênica de CMKLR-1 por qPCR em amostras de tecido gengival palatal de animais controle e hiperlipidêmicos, infectados ou não por $P$. gingivalis. $O$ resultado do gene alvo está expresso em relação à \% de expressão do gene endógeno $\beta$-actina ${ }^{*} p<0,05$ em relação ao grupo $C+V$.

\subsection{Avaliação da Expressão Gênica de RANKL, OPG e Catepsina K em} Gengiva de Animais Controle e Hiperlipidêmico Infectados por $\boldsymbol{P}$. gingivalis

O sistema RANKL/OPG e a enzima catepsina $\mathrm{K}$ foram identificados como importantes componentes moleculares no processo de remodelamento ósseo. Com o objetivo de correlacionar a reabsorção óssea alveolar com a expressão gênica de marcadores osteblastogênicos e osteoclastogênicos, foi realizado qPCR em amostras de tecido gengival dos animais controle e hiperlipidêmicos depois de 60 dias de inoculação por $P$. gingivalis.
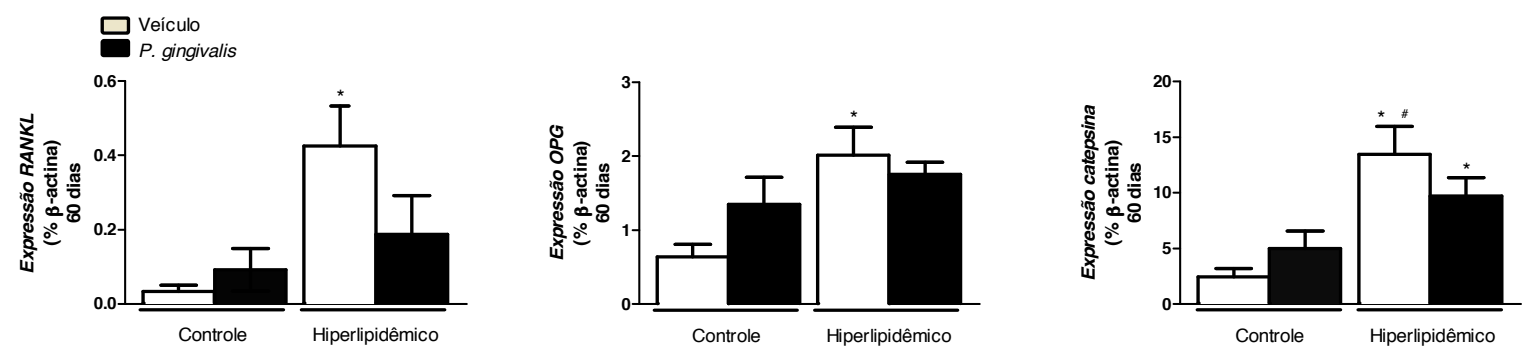

Figura 7. Determinação da expressão gênica de RANKL, OPG e catepsina $K$ em gengiva: Avaliação da expressão gênica de RANKL, OPG e catepsina K por qPCR em amostras de tecido gengival palatal de animais controle e hiperlipidêmicos infectados ou não por $P$. gingivalis; depois de 60 dias de infecção. $O$ resultado do gene alvo está expresso em relação à \% da expressão do gene endógeno $\beta$-actina * $p<0,05$ em relação ao grupo $\mathrm{C}+\mathrm{V}$, ${ }^{*} \mathrm{p}<0,05$ em relação ao grupo $\mathrm{C}+\mathrm{Pg}$.

A Figura 7 mostrou que, 60 dias após inoculação bacteriana, houve um aumento significativo na expressão RANKL, OPG e catepsina $\mathrm{K}$ no tecido gengival dos animais hiperlipidêmicos quando comparados aos animais controle. A expressão de RANKL, OPG e catepsina $K$ foi maior no grupo $H+V \quad(p<0,05)$, quando comparados ao grupo controle $(\mathrm{C}+\mathrm{V})$. $A$ expressão de catepsina $\mathrm{K}$ no grupo $\mathrm{H}+\mathrm{V}$ foi 
estatisticamente diferente $(p<0,05)$ quando comparado também aos grupos $\mathrm{C}+\mathrm{Pg}$. Houve diferença estatisticamente significante entre os grupos $\mathrm{H}+\mathrm{Pg}$ e $\mathrm{C}+\mathrm{V}(\mathrm{p}<0,05)$.

\subsection{Quantificação de Chemerin em Plasma Sanguíneo de Animais Controle e Hiperlipidêmicos Infectados por $\boldsymbol{P}$. gingivalis}

Os níveis circulantes de chemerin estão aumentados em uma série de doenças (Graham et al., 2009; Weigert et al., 2010; Kukla et al., 2010; Gerl et al., 2010) e também, estão relacionados ao IMC (Bozaoglu et al., 2007; Stejskal et al., 2008; Dong et al., 2011). Por isso, com o objetivo de avaliar se a dieta hiperlipidêmica ou a infecção eram capazes de alterar os níveis de chemerin plasmático, foi determinado a concentração de chemerin em plasma sanguíneo nos animais dos diferentes grupos experimentais.

Tabela 5. Concentração plasmática de chemerin.

\begin{tabular}{|c|c|c|c|c|}
\hline & CONTROLE & & HIPERLIPIDËMICO & \\
\hline & Veículo & $P$. gingivalis & Veículo & $P$. gingivalis \\
\hline 15 dias & $27,8 \pm 2$ & $31,5 \pm 3$ & $61,7 \pm 3^{\star \star \star \#}$ & $79,0 \pm 5^{\star \star \star \#+}$ \\
\hline 60 dias & $28,0 \pm 1$ & $36,8 \pm 4$ & $45,5 \pm 3$ & $32,2 \pm 4$ \\
\hline
\end{tabular}

A concentração de chemerin no plasma sanguíneo de animais controle e hiperlipidêmico depois de 15 e 60 dias de infecção por $P$. gingivalis. ${ }^{* \star *} \mathrm{p}<0,0001$ em relação ao grupo $\mathrm{C}+\mathrm{V}$; ${ }^{\#} \mathrm{p}<0,05$ em relação ao grupo $\mathrm{C}+\mathrm{Pg}$; ${ }^{+} \mathrm{p}<0,05$ em relação ao grupo $\mathrm{H}+\mathrm{V} ;{ }^{*} \mathrm{p}<0,05$ em relação ao grupo $\mathrm{C}+\mathrm{V}$.

Os resultados mostraram (Tabela 5) que, no período de 15 dias após a inoculação bacteriana, a concentração plasmática de chemerin foi maior no grupo $\mathrm{H}+\mathrm{V}$ quando comparado aos grupos $\mathrm{C}+\mathrm{V}$ e $\mathrm{C}+\mathrm{Pg}(\mathrm{p}<0,0001)$. Além disso, o grupo $\mathrm{H}+\mathrm{Pg}$ apresentou maior nível de chemerin que o grupo $\mathrm{H}+\mathrm{V}(\mathrm{p}<0,05)$. Em relação ao período de 60 dias após a inoculação bacteriana, embora a concentração plasmática de chemerin seja maior no grupo $\mathrm{H}+\mathrm{V}$ comparado ao grupo $\mathrm{C}+\mathrm{V}$, não foi observada diferença estatisticamente significante entre todos os grupos avaliados.

\subsection{Avaliação da Expressão Gênica de TRAP, Osteocalcina, ALP e Catepsina K em Tecido Ósseo de Animais Controle e Hiperlipidêmico Infectados por $\boldsymbol{P}$. gingivalis}

A avaliação da expressão gênica de TRAP por qPCR em amostras de tecido femural de animais controle e hiperlipidêmicos infectados por $P$. gingivalis mostrou 
que, depois de 15 dias de infecção, o grupo $\mathrm{H}+\mathrm{Pg}$ apresentou maior expressão de TRAP quando comparado ao grupo $\mathrm{C}+\mathrm{Pg}(\mathrm{p}<0,05)$. Após 30 dias de infecção podese notar que houve um aumento na expressão de TRAP nos animais de todos os grupos quando comparado ao grupo de 15 dias. Além disso, foi notada diferença estatística quando comparado o grupo $\mathrm{C}+\mathrm{V}$ e $\mathrm{H}+\mathrm{V}(\mathrm{p}<0,05)$. Depois de 60 dias de infecção foi possível observar que não houve diferença estatística entre os grupos. A expressão de TRAP foi muito maior quando comparada aos primeiros 15 dias de infecção.
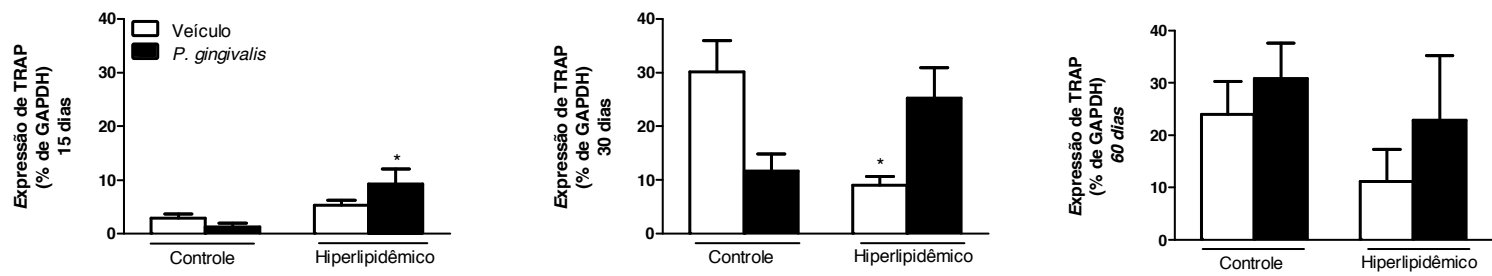

Figura 8. Determinação da expressão gênica de TRAP: Avaliação da expressão gênica de TRAP por qPCR em amostras de tecido ósseo femural de animais controle e hiperlipidêmicos, infectados ou não por $P$. gingivalis; depois de 15, 30 e 60 dias de infecção. O resultado do gene alvo está expresso em relação à \% de expressão do gene endógeno GAPDH. * $\mathrm{p}<0,05$ em relação ao grupo $\mathrm{H}+\mathrm{V}$.

A avaliação da expressão gênica de osteocalcina por qPCR em amostras de tecido femural de animais controle e hiperlipidêmicos infectados por $P$. gingivalis mostrou que, depois de 15 dias de infecção (Figura 9), houve uma diferença estatística entre os grupos $\mathrm{H}+\mathrm{V}$ e $\mathrm{H}+\mathrm{Pg}$ quando comparados ao grupos $\mathrm{C}+\mathrm{V}$ $(p<0,0001)$. Com 30 dias de infecção, não houve diferença estatística entre os grupos, no entanto pode-se notar uma aumento na expressão de osteocalcina nos grupos $\mathrm{C}+\mathrm{V}$ e H+Pg. Depois de 60 dias de infecção, não houve diferença estatística entre os grupos, mas os gráficos mostraram uma aumento na expressão de osteocalcina nos grupos $\mathrm{C}+\mathrm{Pg}, \mathrm{H}+\mathrm{V}$ e $\mathrm{H}+\mathrm{Pg}$ em relação ao $\mathrm{C}+\mathrm{V}$.
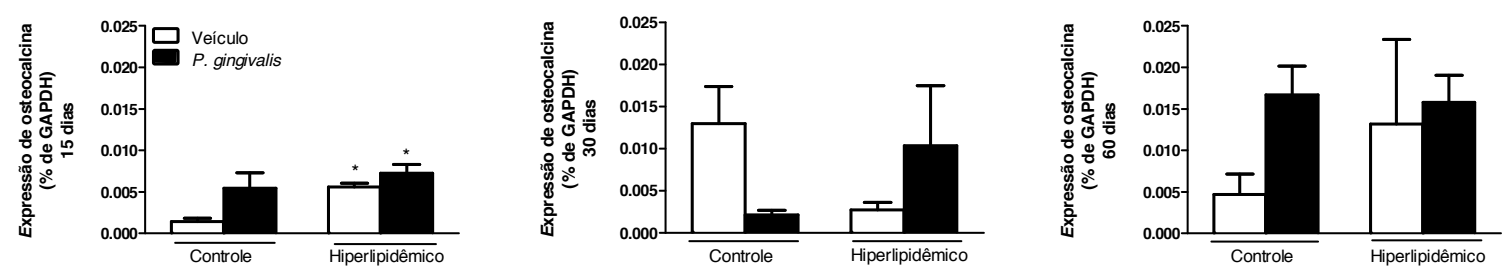

Figura 9. Determinação da expressão gênica de osteocalcina: Avaliação da expressão gênica de osteocalcina por qPCR em amostras de tecido ósseo femural de animais controle e hiperlipidêmicos, infectados ou não por $P$. gingivalis; depois de 15, 30 e 60 dias de doença. $O$ resultado do gene alvo está expresso em relação à \% de expressão do gene endógeno GAPDH ${ }^{* * *} p<0,0001$ em relação ao grupo $\mathrm{C}+\mathrm{V}$. 
A avaliação da expressão gênica de ALP por qPCR em amostras de tecido femural de animais controle e hiperlipidêmicos infectados por $P$. gingivalis (Figura 10) não apresentou diferença estatística entre os grupos, em todos os períodos experimentais. No entanto, os resultados mostraram um aumento na expressão de ALP depois de 60 dias de infecção quando comparado ao grupo experimental de 15 dias.
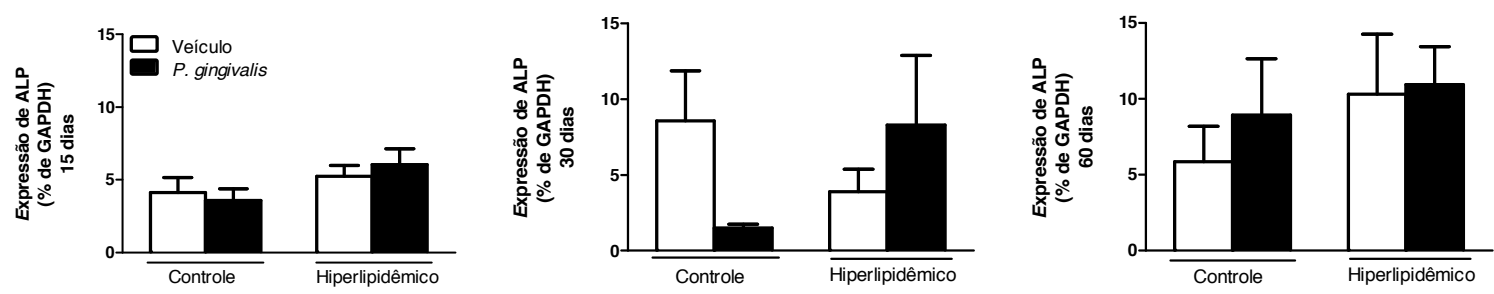

Figura 10. Determinação da expressão gênica de ALP: Avaliação da expressão gênica de ALP por qPCR em amostras de tecido ósseo femural de animais controle e hiperlipidêmicos, infectados ou não por P. gingivalis; depois de 15, 30 e 60 dias de doença. O resultado do gene alvo está expresso em relação à \% de expressão do gene endógeno GAPDH.

A avaliação da expressão gênica de catepsina K por qPCR em amostras de tecido femural de animais controle e hiperlipidêmicos infectados por $P$. gingivalis não mostrou diferença estatística entre os grupos, em todos os períodos experimentais. No entanto, os resultados mostram um aumento na expressão de catepsina $\mathrm{K}$ depois de 30 dias de infecção quando comparado a expressão com 15 dias de infecção.
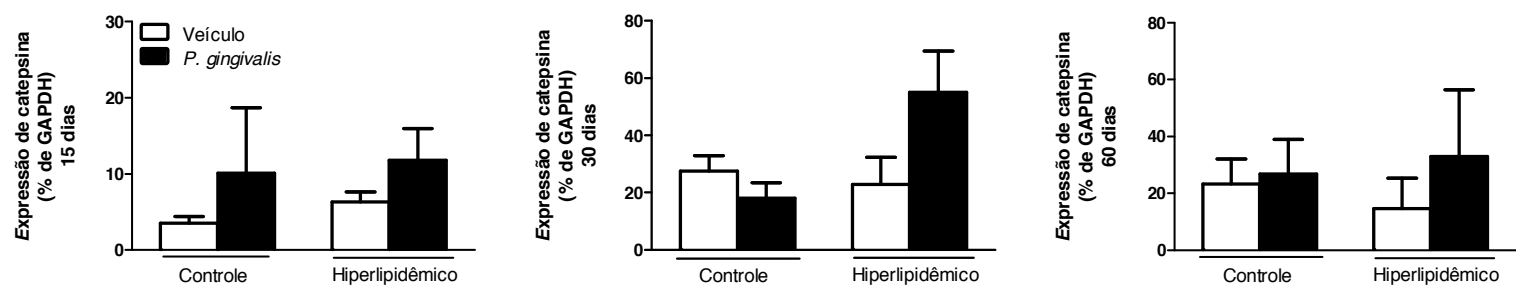

Figura 11. Determinação da expressão gênica de catepsina K: Avaliação da expressão gênica de catepsina K por qPCR em amostras de tecido ósseo femural de animais controle e hiperlipidêmicos, infectados ou não por $P$. gingivalis; depois de 15, 30 e 60 dias de doença. O resultado do gene alvo está expresso em relação à \% da expressão do gene endógeno GAPDH. 


\subsection{Estudo em Cultura Primária de Células Osteoblásticas - Avaliação da Viabilidade Celular, Atividade da Fosfatase Alcalina, Conteúdo de \\ Proteína Total e Formações Nodulares de Matriz Mineralizada}

Para analisarmos o efeito de chemerin em cultura de células osteoblásticas foi realizada uma cultura contendo esta adipocina nas concentrações de $0,1,10,100$ $\mathrm{ng} / \mathrm{mL}$. A avaliação foi realizada quanto à contagem celular, atividade de fosfatase alcalina/conteúdo de proteína total e formações nodulares de matriz mineralizada.

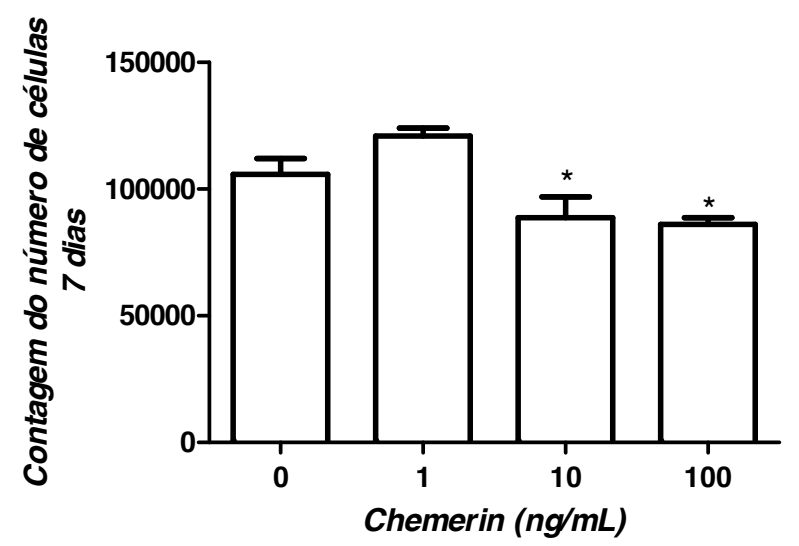

Figura 12. Contagem do número de células: Número de células osteoblásticas em meio contendo a adipocina chemerin na concentração de $0,1,10$ e $100 \mathrm{ng} / \mathrm{mL}$ por um período de 7 dias ( $\left.{ }^{*} p<0,005\right)$.

Os resultados da contagem do número de células (Figura 12) mostrou um menor número de osteoblastos nas culturas contendo chemerin nas concentrações de 10 e $100 \mathrm{ng} / \mathrm{mL}$. Estes valores foram estatisticamente menores quando comparados ao grupo contendo $1 \mathrm{ng} / \mathrm{mL}$ de chemerin $(p<0,005)$.

A análise da fosfatase alcalina mostrou que não houve diferença estatística entre os grupos controle e tratados com chemerin, tanto no sétimo quanto no décimo quarto dias experimentais.
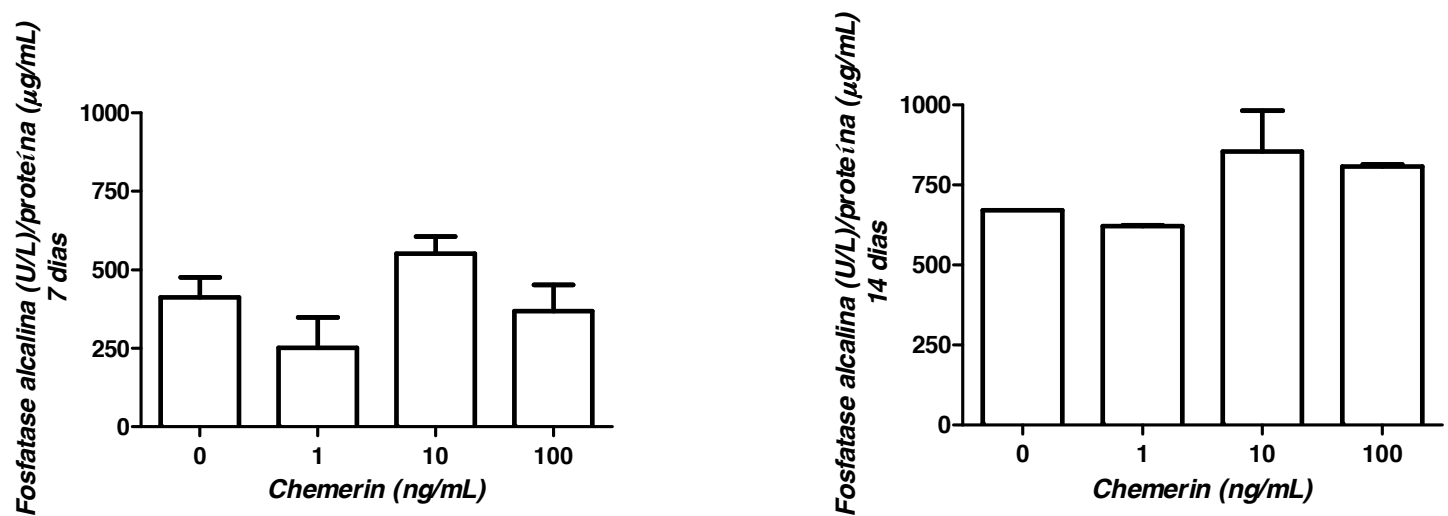

Figura 13. Atividade de fosfatase alcalina/proteína total: Atividade de fosfatase alcalina e proteína total analisada em cultura de células osteoblásticas em meio contendo a adipocina chemerin na concentração de $0,1,10$ e $100 \mathrm{ng} / \mathrm{mL}$, por um período de 7 e 14 dias. 
No experimento realizado com cultura de células osteoblásticas foram analisados os depósitos de cálcio mineralizados aos 21 dias, corados pelo vermelho de alizarina. Os poços foram fotografados e analisados por um programa de imagem (Figura 14). Os grupos contendo chemerin apresentaram calcificação que foram estatisticamente diferentes do grupo controle $(p<0,05)$. No grupo controle foi observado uma área de 16,42 $\mathrm{mm}^{2}$ formada por depósitos mineralizados; o grupo contendo $1 \mathrm{ng} / \mathrm{mL}$ de adipocina chemerin apresentou 48,33 $\mathrm{mm}^{2}$ de área mineralizada, o grupo composto por $10 \mathrm{ng} / \mathrm{mL}$ teve $79,77 \mathrm{~mm}^{2}$ e o grupo com 100 $\mathrm{ng} / \mathrm{mL}$ de chemerin teve $50,28 \mathrm{~mm}^{2}$ de área mineralizada. O grupo composto por 10 $\mathrm{ng} / \mathrm{mL}$ de chemerin também foi diferente estatisticamente do grupo com concentração de $1 \mathrm{ng} / \mathrm{mL}$ de chemerin.
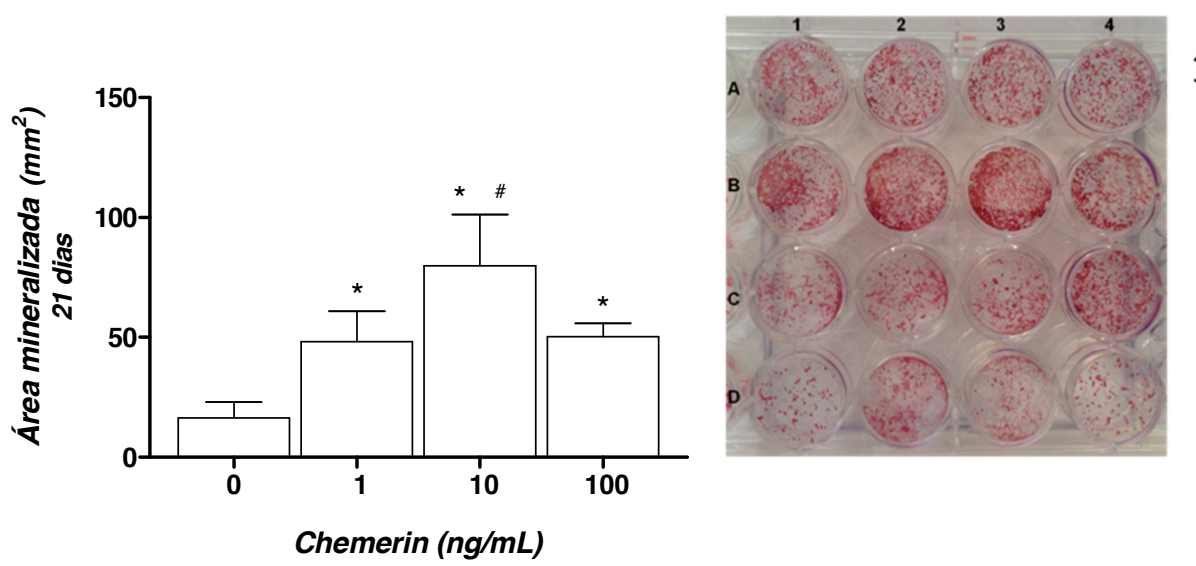

$100 \mathrm{ng} / \mathrm{mL}$

$10 \mathrm{ng} / \mathrm{mL}$

$1 \mathrm{ng} / \mathrm{mL}$

$0 \mathrm{ng} / \mathrm{mL}$

Figura 14. Determinação da área mineralizada $\left(\mathrm{mm}^{2}\right)$ em cultura de osteoblastos com chemerin: Áreas mineralizadas coradas pelo vermelho de Alizarina aos 21 dias de cultura de células osteoblásticas em meio contendo a adipocina chemerin nas concentrações de $0,1,10$ e $100 \mathrm{ng} / \mathrm{mL}$ ${ }^{*} p<0,05$ em relação ao grupo contendo $0 \mathrm{ng} / \mathrm{mL} e^{\#} p<0,05$ em relação ao grupo contendo $1 \mathrm{ng} / \mathrm{mL}$.

\subsection{Avaliação da Expressão Gênica de RANKL e OPG em Cultura de Células Osteoblásticas}

O sistema RANKL e OPG foram identificados como importantes componentes moleculares do processo de remodelação óssea. Por isso, foi realizada a determinação da expressão gênica destes fatores em cultura de células osteoblásticas na tentativa de analisar seu comportamento frente diferentes concentrações da adipocina chemerin. 

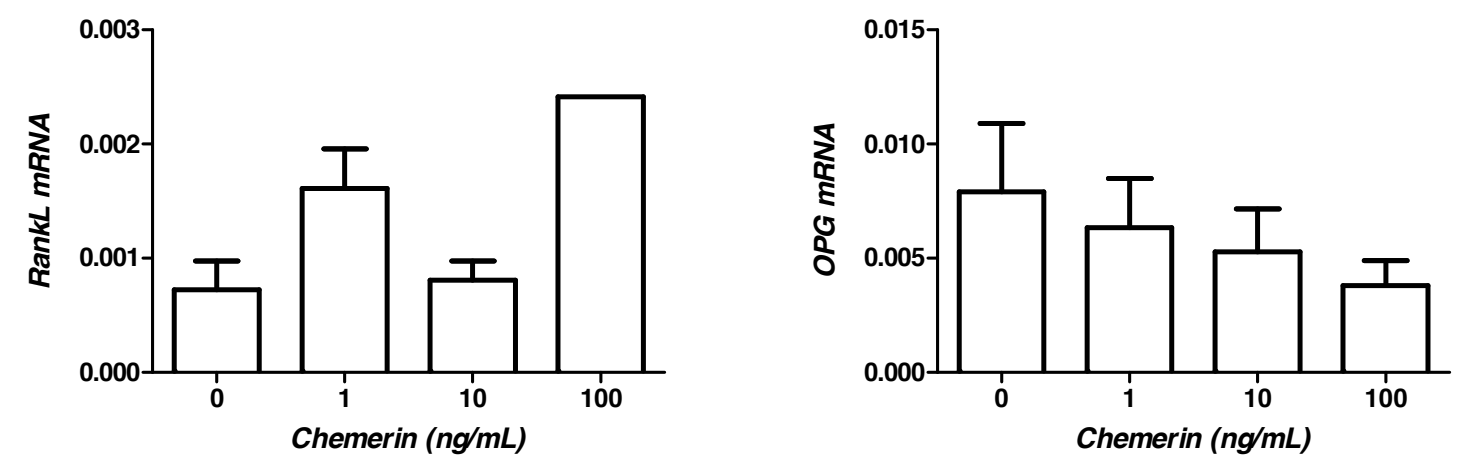

Figura 15. Determinação da expressão gênica de RANKL e OPG em cultura de células osteoblásticas: Avaliação da expressão gênica de RANKL E OPG por qPCR em cultura de células osteoblásticas por um período de 10 dias.

Embora observa-se uma maior expressão de RANKL na cultura com 1 $\mathrm{ng} / \mathrm{mL}$ de chemerin, a Figura 15 mostra que não houve diferença estatística significativa entre os grupos. Da mesma forma a adição de chemerin na cultura de osteoblastos não alterou a expressão de OPG aos 10 dias de cultura.

\subsection{Estudo em Cultura Primária de Células Osteoclásticas - Avaliação da Área Reabsorvida}

O estudo em cultura primária de células osteoclásticas mostrou que a adipocina chemerin aumentou a atividade e reabsorção da matriz mineralizada pelos osteoclastos quando comparada à cultura contendo meio com apenas MCSF + RANKL (Figura 16).
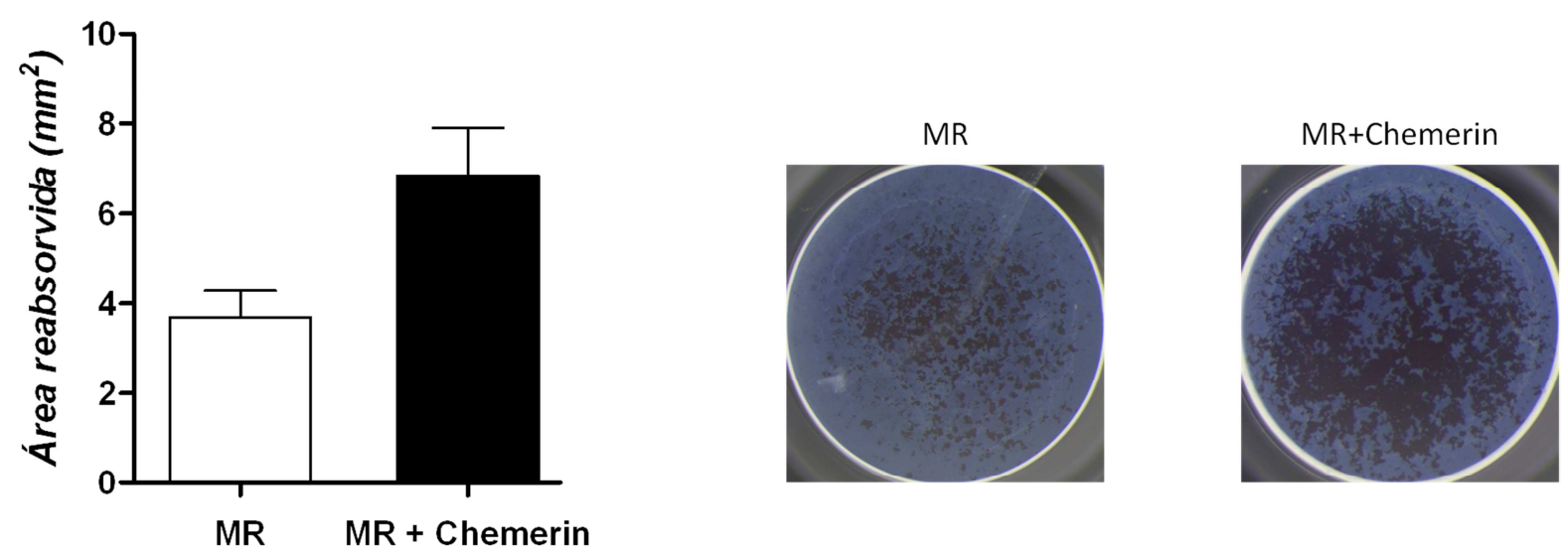

Figura 16. Determinação de área reabsorvida $\left(\mathrm{mm}^{2}\right)$ em cultura de células osteoclásticas com chemerin: Cultura de células osteoclásticas com meio contendo a adipocina chemerin na concentração de $10 \mathrm{ng} / \mathrm{mL}$. A imagem mostra a área mineralizada reabsorvida e corada pelo azul de toluidina, aos 7 dias (MR= M-CSF + RANKL). 

Discussão 



\section{DISCUSSÃO}

Diversos estudos tem mostrado que a obesidade e o sobrepeso são importantes fatores de risco para o desenvolvimento da doença periodontal (Perlstein e Bissada, 1977; Saito et al., 1998; Saito et al., 2001; Al-Zanhani et al., 2003; Ritchie, 2007; Khader et al., 2009; Haffajee and Socransky, 2009; Bawadi et al., 2011; Kim et al., 2011; Gorman et al., 2012). Sabe-se que o tecido adiposo representa um reservatório de mediadores inflamatórios e assim, pode exacerbar a resposta inflamatória em patologias como no diabetes, artrite reumatóide, e também na doença periodontal. As células do tecido adiposo são capazes de sintetizar e secretar inúmeras proteínas denominadas adipocinas, dentre elas a adipocina chemerin (Bozaoglu et al., 2007) que atua em numerosos processos fisiológicos como metabolismo e diferenciação celular (Roman et al., 2012).

Chemerin tem sido correlacionado com diversas patologias uma vez que os níveis circulantes de chemerin estão aumentados na colite ulcerativa e doença de Crohn (Weigert et al., 2010), doença hepática não-alcólica (Kukla et al., 2010), doença desmielinizante autoimmune (Graham et al., 2009), lupus eritematoso (Gerl et al., 2010) e doença periodontal (Ozcan et al., 2014). Além disso, níveis séricos da adipocina chemerin estão aumentados em pacientes obesos (Ernst et al., 2010; Ernst and Sinal, 2010).

Salekzamani et al. (2011) avaliaram a correlação entre a composição corporal em homens e seu padrão periodontal. Os pacientes foram submetidos à tomada de medidas antropométricas, dentre elas IMC, circunferência abdominal, relação cintura-quadril e porcentagem de gordura subcutânea. Os autores observaram que no grupo de pacientes com periodontite, o IMC e circunferência abdominal foram muito maiores do que nos grupos saudáveis ou com gengivite. Em outro trabalho, Pataro et al. (2012) avaliaram em mulheres brasileiras, se existia uma relação entre IMC e a condição periodontal. Esses autores constataram que a periodontite está positivamente associada também à obesidade em mulheres.

Com base nos dados apresentados, o presente projeto pretendeu avaliar o papel da adipocina Chemerin na perda óssea observada na doença periodontal de camundongos hiperlipidêmicos. A escolha do modelo de hiperlipidemia foi criteriosa uma vez que existe na literatura vários modelos experimentais de obesidade que envolvem tanto alteração na qualidade da alimentação oferecida ao animal quanto 
manipulação genética (Speakman et al., 2007). Alguns modelos animais têm sido utilizados para estudar o efeito da obesidade sobre o desenvolvimento ou gravidade de doença periodontal.

Alguns pesquisadores desenvolveram animais obesos por manipulação genética como o rato Zucker. Esta mutação genética (fa/fa) os impedem de sintetizar os receptores de leptina e com isso, desencadeia um reflexo de saciedade com consequente hiperfagia e desenvolvimento do quadro de obesidade (Rosmond et al., 2004). Jin et al. (2014) induziram a periodontite em ratos Zucker através da injeção de lipopolissacáride (LPS) isolados da bactéria Aggregatibacter actinomycetemcomitans, e monstraram que a reabsorção óssea foi mais severa em ratos Zucker quando comparado à ratos controle.

Os modelos de obesidade que envolvem mudanças na dieta dos animais consistem em modificações da ração, seja enriquecida com gordura (high-fat), açúcares (high-sucrose) ou ambos (Naderali et al., 2001; Naderali et al., 2003). Essas modificações mimetizam hábitos alimentares inadequados com alto conteúdo energético como dietas ricas em sanduiches, frituras e doces. Dentre estas, há a famosa dieta de cafeteria, onde se introduz, na alimentação do animal, ítens como chocolate, bacon, biscoito, queijo ou outro alimento com alto teor calórico e baixo valor nutricional consumido pelos humanos (Lopez et al., 2003). Verzeletti et al. (2012) mostraram que a dieta de cafeteria, rica em açúcar e gordura aumentou significativamente o peso dos animais deste grupo. Os autores mostraram que a obesidade induzida por esta dieta estava correlacionado com maior perda óssea alveolar induzida por ligadura. Os animais obesos mostraram valores mais elevados de perda óssea na face palatina dos dentes que os animais não obesos.

Dados controversos são mostrados por Simch et al., 2008 que também avaliaram a perda óssea alveolar induzida por ligadura em ratos obesos induzidos pela dieta de cafeteria como método de indução de obesidade. Diferentemente do grupo do Verzeletti, estes autores mostraram que o estabelecimento e progressão da perda óssea alveolar não foi influenciada pelo peso corpóreo.

Amar et al. (2007) utilizou outro modelo de obesidade, que foi pela ração enriquecida com gordura (high-fat) e a infecção com Porphyromonas gingivalis para induzir a periodontite. Estes autores mostraram que os animais que receberam dieta rica em gordura apresentaram maior reabsorção óssea alveolar que o controle. 
Diante dos diversos modelos de obesidade publicados, a escolha de um modelo para este estudo levou em consideração vários aspectos, como baixo custo, fácil reprodutibilidade, manuseio, conservação, fácil aceitação pelos animais e que mantivesse o formato de pellets. Desta forma, foi escolhida a ração hiperlipídica com $34,5 \%$ de colesterol no formato de pellets e com consistência semelhante a ração controle (Pragsoluções, Jaú, Brasil).

De forma inesperada, a análise do ganho de peso dos animais mostrou que no presente estudo, os animais que receberam a dieta hiperlipídica não apresentaram diferença estatisticamente significativa de peso corporal quando comparados aos animais controle (FIGURA 1). Corroborando com nossos resultados, Sambon et al. (2009) trabalharam com uma dieta com $20 \%$ de lipídios e que era composta por uma ração controle associada à amendoim, chocolate e biscoite de amido de milho. Estes autores mostraram que, essa dieta hiperlipídica também não alterou o ganho de peso dos animais. Segundo estes autores, dietas ricas em gordura reduzem a necessidade alimentar do animal e aumentam a eficiência metabólica, o que explicaria o porquê do animal não ganhar peso, além do normal. Outra possível explicação para a semelhança do peso dos animais controle e hiperlipidêmicos observado no presente trabalho seria a quantidade de gordura presente na ração. Enquanto a dieta utilizada no presente trabalho apresentava $34,5 \%$ de colesterol, a grande maioria dos modelos de obesidade, que proporcionaram aumento de peso dos animais, utilizaram uma porcentagem maior de calorias na dieta alcançado pela presença de banha de porco (Da Silva et al., 2010), leite condensado (De Moraes et al., 2008) ou dieta de cafeteria (DeSchepper et al., 1998; Lopez et al., 2003) na alimentação.

No presente trabalho não adotamos a dieta com porcentagem maior de colesterol visto que, a ração produzida com uma altos níveis de colesterol apresenta uma consistência amolecida, o que não permite a formação de pellets de ração, interfere no ato de roer dos animais e prejudica o desgaste fisiológico nos dentes. Além disso, sabe-se que a consistência da ração pode influenciar na doença periodontal, ou seja, a consistência menor da ração leva ao desenvolvimento da doença periodontal (Björnsson et al., 2003).

Embora o modelo de hiperlipidemia adotado nesta pesquisa não tenha alterado o ganho de peso dos animais, ele foi eficaz no aumento da adiposidade corporal indicados aumento dos tecidos adiposos epididimal e retroperitoneal no 
grupo hiperlipidêmico quando comparado ao grupo controle (Figura 2); além disso, observou-se um aumento nos níveis de colesterol e chemerin no plasma sanguíneo dos animais (Tabela 2-4 e Tabela 5). Desta forma, foi possível concluir que o modelo de indução de hiperlipidemia utilizada neste estudo foi eficaz, produzindo alteração metabólica nos animais quando comparado aos controle.

Há vários modelos animais descritos na literatura e utilizados para investigar a doença periodontal; no presente estudo, o modelo adotado para indução da periodontite experimental foi a inoculação oral por Porphyromonas gingivalis da cepa W83. Este modelo mostrou-se efetivo, uma vez que os animais controle submetidos à inoculação oral por Porphyromonas gingivalis apresentaram perda óssea alveolar mensurável nos molares maxilares, em todos os períodos avaliados. Este resultado corrobora com diversos outros trabalhos que utilizaram bactérias periodontopatogênicas (Queiroz-Junior et al., 2012; Wang et al., 2013; Yoshinaka et al., 2014) ou a mesma cepa de bactéria (Sasaki et al., 2004; 2008; 2010; Wilensky et al., 2013; Prates et al., 2014).

O presente estudo monstra que a reabsorção óssea nos molares do grupo hiperlipidêmico foi maior que o observado no grupo controle, ou seja, a hiperlipidemia agravou a doença periodontal, corroborando com diversos trabalhos da literatura que mostram a influência da alteração lipidêmica na doença periodontal. Importante destacar ainda que, o grupo hiperlipidêmico e não infectado apresentou o mesmo padrão de reabsorção óssea do grupo hiperlipidêmico e infectado em todos os períodos experimentais avaliados 15, 30 e 60 dias após infecção por $P$. gingivalis. Ou seja, o estudo morfométrico permitiu constatar que a infecção pela $P$. gingivalis não exacerbou a reabsorção óssea causada no grupo hiperlipidêmico; a hiperlipidemia parece ter proporcionado reabsorção máxima, haja visto que o grupo $\mathrm{H}+\mathrm{V}$ e o grupo $\mathrm{H}+\mathrm{Pg}$ apresentaram padrões de reabsorção óssea semelhantes (Figura 4).

A obesidade e a doença periodontal provavelmente estão correlacionadas ao aumento de fatores pró-inflamatórios nos tecidos periodontais de indivíduos obesos. Tem sido mostrado que o tecido adiposo branco, principalmente, o tecido adiposo visceral, secreta adipocinas que levam o organismo a um estado inflamatório crônico e resposta imune alterada (Wozniak et al., 2009). Dentre as citocinas já conhecidas, o Fator de Necrose Tumoral (TNF) - a que é uma citocina pró-inflamatória, provavelmente está aumentada na obesidade e inflamação 
(Hotamisligil et al., 1993), assim como está envolvida na progressão da periodontite (Preshaw and Taylor, 2011). A interleucina (IL) - 6, também com função próinflamatória está envolvimento tanto na obesidade (Ouch et al., 2011) quanto na periodontite (Preshaw and Taylor, 2011).

A Leptina é uma adipocina tecidual pro-inflamatória que tem seus níveis circulantes associado à severidade da doença periodontal (Johnson and Serio, 2001). Existem ainda, as adipocinas com papel anti-inflamatórios, como a adiponectina. Os níveis plasmáticos de adiponectina estão diminuídos em pacientes obesos, sugerindo sua reduzida função na periodontite (Yamaguchi et al., 2010). Dentre as mais de 50 adipocinas que existem, a adipocina chemerin é pouco relatada na literatura quando relacionada à doença periodontal e reabsorção óssea. De acordo com a literatura, os níveis de chemerin na saliva estão aumentados em pacientes com doença periodontal quando comparados com pacientes com gengivite, ou gengiva saudável (Ozcan et al., 2014). Com o objetivo de avaliar o papel de chemerin sobre a reabsorção óssea induzida por periodontite em animais submetidos à dieta hiperlipidêmica, inicialmente foi determinada a concentração desta adipocina no plasma sanguíneo. Os resultados mostraram um aumento na concentração de chemerin no grupo hiperlipidêmico quando comparado ao grupo controle depois de 15 dias de infecção (Tabela 5). Após 60 dias, observou uma queda na concentração de chemerin quando comparado ao primeiro período experimental e a concentração plasmática foi semelhante entre os grupos estudados. Esses dados confirmam que chemerin está aumentada nos animais hiperlipidêmicos e que possivelmente esta adipocina apresenta um papel no desenvolvimento da periodontite experimental.

Considerando a presença da adipocina chemerin no plasma sanguíneo dos animais hiperlipidêmicos, foi investigada a presença desta adipocina no tecido gengival e seu possível papel na perda óssea induzida por periodontite. Os resultados mostraram que tanto chemerin (FIGURA 5) quanto o seu receptor CMKLR-1 (FIGURA 6) estavam expressos na gengiva principalmente, após 60 dias de infecção, período em que a expressão estava maior. Neste período experimental foi observado que o grupo $\mathrm{H}+\mathrm{V}$ apresentou maior expressão de chemerin e seu receptor CMKLR-1 quando comparado ao grupo controle $(\mathrm{C}+\mathrm{V})$. Neste estudo, mostrou-se inclusive, um aumento na expressão de chemerin e seu receptor no grupo controle infectado quando comparado ao grupo controle não infectado, 
sugerindo uma possível participação da adipocina chemerin na doença periodontal mesmo quando um quadro de obesidade/sobrepeso não esteja instalado. Estes dados estão de acordo com as informações obtidas em uma recente pesquisa feita com indivíduos não obesos, que mostrou uma maior concentração da adipocina chemerin em amostras de saliva de pacientes com periodontite quando comparados à pacientes com gengivite e à pacientes com boa saúde bucal (Ozcan et al., 2014). Complementando os resultados encontrados no plasma sanguíneo, o aumento de expressão de chemerin na gengiva depois da inoculação bacteriana, no grupo controle, pressupõe que a concentração de chemerin no organismo é aumentada frente à um quandro infeccioso; e ainda, exacerbada pelo aumento da adiposidade corporal.

As células tronco mesenquimais da medula são multipotentes e se diferenciam em várias linhagens celulares como osteoblastos e adipócitos (Phinney et al., 1999). Dentro da medula óssea, a diferenciação destas células é equilibrada de forma competitiva, no entanto, em condições desfavoráveis como em casos de osteoporose, o balanço é interrompido, levando a adipogênese. A manutenção do tecido ósseo saudável requer um equilíbrio bem coordenado entre os processos de formação e reabsorção óssea. Os adipócitos não contribuem diretamente para a formação óssea, mas podem influenciar na remodelação óssea através da liberação de moléculas bioativas de sinalização como a adipocina chemerin. A diferenciação de adipócitos a partir de células mesenquimais da medula aumentam drasticamente a expressão e secreção de chemerin. Quando impedida a expressão de chemerin ou o bloqueio do seu receptor CMKLR-1 ocorre uma interferência na diferenciação dos adipócitos e, em contraste, há um aumento na expressão de genes marcadores de osteoblastogênese e aumento de mineralização (Muruganandan, Roman and Sinal, 2010). Esses dados mostram que a adipocina chemerin pode interferir na via equilibrada de formação de osteoblastos e adipócitos.

Muruganandan et al. (2013) avaliaram o papel da chemerin e seu receptor em células tronco hematopoiéticas (HSC) diferenciando em osteoclastos. Os autores relatam que o bloqueio de chemerin com anticorpo de bloqueio inibe a diferenciação das células HSC em osteoclastos, e consequente diminuição de reabsorção de matriz mineralizada. Quando retirado o efeito do anticorpo de bloqueio com chemerin, retornando a diferenciação osteoclastogênica e reabsorção óssea. Os 
dados mostram que a sinalização autócrina de chemerin é essencial para a diferenciação de HSC em osteoclastos.

Estes dados da literatura podem explicar o resultado encontrado nesta tese quando se afirma que os animais hiperlipidêmicos não infectados tiveram o mesmo padrão de reabsorção óssea que aos animais hiperlipidêmicos infectados. O aumento de peso dos tecidos adiposos (FIGURA 2) causado pela hiperlipidêmia estaria aumentando a produção de chemerin, que por sua vez, estaria estimulando as células mesenquimais da medula à diferenciação de adipócitos e inibindo a diferenciação em osteoblastos; assim como estimulando as células hematopoiéticas a se diferenciarem em osteoclastos. Consequentemente há uma alteração do metabolismo ósseo, diminuindo a mineralização e aumentando reabsorção óssea.

O sistema RANKL/OPG e enzimas como catepsina K, osteocalcina, TRAP e ALP foram identificados como importantes componentes moleculares no processo de formação e ativação de osteoclastos e osteoblastos, e consequentemente de remodelamento ósseo. Com o objetivo de entender a reabsorção óssea alveolar ocorrida nos animais hiperlipidêmicos, foi realizada a análise da expressão gênica de marcadores osteblastogênicos e osteoclastogênicos por qPCR nas amostras de tecido gengival dos animais controle e hiperlipidêmicos depois da inoculação por $P$. gingivalis. No tecido gengival foi demonstrado que a expressão de RANKL, OPG e catepsina $\mathrm{K}$ foi muito maior depois de 60 dias de infecção; assim como a expressão de chemerin e seu receptor CMKLR-1. Os animais hiperlipidêmicos tiveram maior expressão de RANKL, OPG e catepsina $\mathrm{K}$ que os animais controle.

O tecido ósseo aloja e protege a medula óssea que é fonte de células precursoras de osteoblastos e osteoclastos. Considerando que os níveis circulantes de chemerin estão aumentados nos animais com periodontite e hiperlipidêmcos, e estes animais apresentaram maior perda óssea, nesta fase do projeto, avaliamos a expressão dos marcadores de osteoblastos e osteoclastos na medula óssea que é fonte dessas células precursoras. Quando analisado a expressão de marcadores destes tipos celulares no fêmur observou que, animais hiperlipidêmicos apresentam maior expressão de marcadores tanto de osteoclastos quanto osteoblastos. Os resultados sugerem que chemerin não apresenta um efeito claro sobre a medula óssea direcionando o equilíbrio para células precursoras de osteoblastos ou osteoclastos. 
Com o objetivo de entender o efeito direto de chemerin sobre esses dois tipos celulares responsáveis pela remodelamento ósseo, foi realizado experimentos in vitro de osteoblastos e osteoclastos estimulados com chemerin. Em cultura de osteoblastos, observou-se que chemerin pode inibir a proliferação de osteoblastos em doses altas (10 e $100 \mathrm{ng} / \mathrm{mL}$ ) mas não altera significativamente os marcadores de diferenciação. As culturas contendo chemerin em concentrações maiores, $10 \mathrm{e}$ $100 \mathrm{ng} / \mathrm{mL}$ corroboram com o trabalho de Muruganandan, Roman e Sinal (2010) que mostram que adipocina chemerin inibe a diferenciação de células osteoblásticas. Neste estudo, observamos ainda a atividade dos osteoblastos por avaliação da área de depósitos mineralizados de cálcio corados pelo vermelho de alizarin. Pode se observar que chemerin aumentou a atividade dos osteoblastos evidenciados pela maior área de mineralização, quando comparadas ao grupo controle.

$O$ estudo em cultura de osteoclastos mostrou que a adipocina chemerin apresentou um efeito de aumento na atividade celular e reabsorção da matriz mineralizada pelos osteoclastos quando comparada à cultura contendo meio com apenas MCSF + RANKL. Esses dados corroboram com o trabalho de Muruganandan et al. (2013) que mostrou que chemerin potencializa a osteoclastogênese e reabsorção óssea de matriz mineralizada.

Os ossos são estruturas altamente dinâmicas que sofrem constante remodelação durante toda a vida do organismo. O remodelamento ósseo é o resultado da atividade sincronizada entre osteoclastos e osteoblastos e é um processo extremamente complexo, controlado pela interação de forças dinâmicas, hormônios, citocinas, prostaglandinas e fatores de crescimento. Sabe-se que as citocinas podem modificar a remodelação óssea, atuando na formação e reabsorção óssea. Neste trabalho podemos constatar que a adipocina chemerin influencia tanto na diferenciação e atividade de osteoblastos quanto de osteoclastos in vitro. Os marcadores ósseos expressos em tecido gengival nos permite dizer que estão sofrendo a influência da alteração hiperlipidêmica no organismo causada pela dieta, haja visto o aumento destes marcadores nos animais deste grupo.

No presente estudo o balanço remodelamento/reabsorção óssea no grupo hiperlipidêmico foi favorável à reabsorção óssea como demonstrado pelo estudo morfométrico. Pressupõe a participação da adipocina chemerin neste processo, no entanto não se pode conferir a esta única adipocina a responsabilidade pela perda óssea, pois o organismo é dinâmico e sofre a influência de diversas outras 
adipocinas que não foram investigadas no presente estudo. Com isso, seria de suma importância estudos adicionais para elucidar o papel de chemerin na doença periodontal, principalmente frente à sua deleção genética e resposta na reabsorção óssea alveolar de animais hiperlipidêmicos com e sem infecção. 

Conclusão 

6. Conclusão

Assim, em função dos resultados encontrados neste trabalho conclui-se que:

$\checkmark$ A hiperlipidemia provoca reabsorção óssea alveolar semelhante ao observado com infecção oral com $P$. gingivalis

$\checkmark$ Expressão de chemerin na gengiva e plasma se correlacionam com marcadores de osteoclastos no tecido gengival e com a reabsorção alveolar

$\checkmark$ A adipocina chemerin aumenta atividade de osteoblastos e osteoclastos. 

REFERÊNCIAS 



\section{REFERÊNCIAS}

Ahima RS. Adipose tissue as an endocrine organ. Obesity. 2006;14:242-49.

Ahima RS, Flier JS. Adipose tissue as an endocrine organ. Trends in endocrinology and metabolism. TEM. 2000;11(8):327-32.

Al-Zahrani MS, Bissada NF, Borawskit EA. Obesity and periodontal diseasein young, middle-aged, and older adults. J Periodontol. 2003;74:610-15.

Amar S, Zhou Q, Shaik-Dasthagirisaheb Y, Leeman S. Diet-induced obesity in mice causes changes in immune responses and bone loss Disease and Obesity: A Systematic Review and Meta-Analysis. J Periodontol. 2010;81(12):1708-24.

Amar S, Zhou Q, Shaik-Dasthagirisaheb Y, Leeman S. Diet-induced obesity in mice causes changes in immune responses and bone loss manifested by bacterial challenge. Proc Natl Acad Sci. 2007;104:20466-471.

Arçari DP, Bartchewsky W, Dos Santos TW, Oliveira KA, Funck A, Pedrazzoli J, De Souza MF, Saad MJ, Bastos DH, Gambero A, Carvalho O, Ribeirao ML. Antiobesity Effects of yerba maté extract (Ilex paraguariensis) in High-fat Diet-Induced Obese Mice. Obesity. 2009;17(12):2127-2133.

Barnea M, Shamay A, Stark AH, Madar Z. A high-fat diet has a tissue-specific effect on adiponectin and related enzyme expres- sion. Obesity. 2006;14(12):2145-53.

Bastard JP, Maachi M, Lagathu C, Kim MJ, Caron M, Vital H, Capeau J, Feve B. Recent advances in the relationship between obesity, inflammation and insulin resistance. Eur. Cytokine Netw. 2006;17(1):4-12.

Bawadi HA, Khader YS, Haroun TF, Al-Omari M, Tayyem RF: The association between periodontal disease, physical activity and healthy diet among adults in Jordan. J Periodontal Res. 2011;46(1):74-81.

Bergstrom JS, Eliasson S, Dock J. A 10-year prospective study of tobacco smoking and periodontal health. J Periodontol. 2000;71(8):1338-47. 
Bjornsson MJ, Velschow S, Stoltze K, Havemose-Poulsen A, Schou S, Holmstrup P. The influence of diet consistence, drinking water and bedding on periodontal disease in Sprague-Dawley rats. J Periodontal Res. 2003;38(6):543-50.

Borrell LN, Papapanou PN. Analytical epidemiology of periodontitis. J Clin Periodontol. 2005;32(6):132-58.

Bouchard P. Boutouyrie P, Mattout C, Bourgeois D. Risk assessment for severe clinical attachment loss in an adult population. J Periodontol. 2006;77(3):479-89.

Bozaoglu K, Bolton K, McMillan J, Zimmet P, Jowett J, Collier G, Walder K, Segal D. Chemerin is a novel adipokine associated with obesity and metabolic syndrome. Endocrinol. 2007;148(10):4687-94.

Brianezzi LFF, Al-Ahj LP, Prestes LA, Andreatta LM, Vasconcelos LRM, Marsicano JA, Peres AS, Peres SHCS. Impact of obesity on oral health: a Literature review. RFO. 2013;18(2):211-216.

Buettner R, Schoölmerich J, Bollheimer LC. High-fat diets: modeling the metabolic disorders of human obesity in rodents. Obesity. 2007;15(4):798-808.

Buettner R, Parhofer KG, Woenckhaus M, Wrede CE, Kunz-Schu- ghart LA, Schoölmerich J, et al. Defining high-fat-diet rat models: metabolic and molecular effects of different fat types. J Mol Endocrinol. 2006;36:485-501.

Burguera B, Hofbauer LC, Thomas T, Goeri, F, Evans GL, Khosla S, Riggs BL, Turner RT. Leptin reduces oariectomy-induced bone loss in rats. Endocrinology. 2001;142:3546-53.

Cani PD, Bibiloni R, Knauf C, Waget A, Neyrinck AM, Delzenne NM, et al. Changes in gut microbiota control metabolic endoto- xemia-induced inflammation in high-fat diet-induced obesity and diabetes in mice. Diabetes. 2008;57:1470-81.

Cinti S. The Adipose Organ. Adipose Tissue and Adipokines in Health and Disease. Nutrition and Health. 2007;3-19. 
Dalla Vecchia CF, Susin C, Rosing CK, Oppermann RV, Albandar JM. Overweight and obesity as risk indicators for periodontitis in adults. J. Periodontol. 2005;76(10):1721-28.

Dang ZC, van Bezooijen RL, Karperien M, Papapoulos SE, Lowik CW. Exposure of KS483 cells to estrogen enhances osteogenesis and inhibits adipogenesis. J Bone Miner Res. 2002;17:394-405.

Da Silva AS, Pauli JR, Ropelle ER, Oliveira AG, Cintra DE, De Souza CT et al. Exercise intensity, inflammatory signaling and insulin resistance in obese rats. Med Sci Sports Exerc. 2010;42(12):2180-8.

De Moraes C, Davel AP, Rossoni LV, Antunes E, Zanesco A. Exercise training improves relaxation response and SOD-1 expression in aortic and mesenteric rings from high caloric diet-fed rats. BMC Physiol. 2008;29:8-12.

De Oliveira PT, Nanci A. Nanotexturing of titanium-based surfaces upregulates expression of boné sialoprotein and osteopontin by cultured osteogenic cells. Biomaterials. 2004;25:403-13.

De Oliveira PT, Zalzal SF, Irie K, Nanci A. Early expression of bone matrix proteins in osteogenic cell cultures. Journal Histochem Cytochem. 2003;51:633-41.

De Schepper JA, Smitz JP, Zhou XL, Louis O, Velkeniers BE, Vanhaelst L. Cafeteria diet-induced obesity is associated with a low spontaneous growth hormone secretion and normal plasma insulin-like growth factor-I concentrations. Grow Horm IGF Res. 1998;8(5):397-401.

Dong B, Ji W, Zhang Y. Elevated serum chemerin levels are associated with the presence of coronary artery disease in patients with metabolic syndrome. Intern Med. 2011;50(10):1093-7.

Du XY, Leung LL. Proteolytic regulatory mechanism of chemerin bioactivity. Acta Biochim Biophys Sin (Shanghai). 2009;41(12):973-9. 
Dulloo AG, jacquet J., Solinas G., Montani JP, Schutz Y. Body composition phenotypes in pathways to obesity and the metabolic syndrome. International Journal of Obesity. 2010;34:4-17.

Duque G, Macoritto M, Kremer R. 1,25(OH)2D3 inhibits bone marrow adipogenesis in senescence accelerated mice (SAM-P/6) by decreasing the expression of peroxisome proliferator-activated receptor g2 (PPARg2). Exp Gerontol. 2004;39:33338.

Ebersole JL, Steffen MJ, Thomas MV, Al-Sabbagh M. Smoking-related cotinine levels and host responses in chronic periodontitis. Journal of Periodontal Research. 2014;49(5):642-51.

Ernst MC, Issa M, Goralski KB, Sinal CJ. Chemerin exacerbates glucose intolerance in mouse models of obesity and diabetes. Endocrinology. 2010;151(5):1998-07.

Ernst MC, Sinal CJ. Chemerin: at the crossroads of inflammation and obesity. Trends in endocrinology and metabolism: TEM. 2010;21(11):660-7.

Farmer SR. Obesity: Be cool, lose weight. Nature. 2009;458(7240):839-40.

Fonseca-Alaniz MH, Takada J, Alonso-Vale MIC, Lima FB. O tecido adiposo como centro regulador do metabolismo. Arq. Bras. Endocrinol. Metab. 2006;50(2):216-229.

Fonseca-Alaniz MH, Takada J, Alonso-Vale MIC, Lima FB. Adipose tissue as na endocrine organ: from theory to practice. Jornal da Pediatria. 2007;83(5):192-203.

Fraloub JC, Ogg-Diamantino R, Fernandes-Santos C, Aguila MB, Mandarim-DeLacerda CA. A mouse model of metebolic syndro- me: insulin resistance, fatty liver and non-alcoholic fatty pancreas disease (NAFPD) in c57bl/6 mice fed a high fat diet. J Clin Bio- chem Nutr. 2010;46(3):1-12.

Frederico L. Novos dados da obesidade no mundo. Fica uma pergunta no ar. In: Inter-relação entre doença periodontal, diabetes e obesidade. Braz. J. Periodontol. 2011;21(3):16-21. 
Garlet GP, Cardoso CR, Campanelli AP, Ferreira BR, Avila-Campos MJ, Cunha FQ, Silva JS. The dual role of p55 tumour necrosis factor-alpha receptor in Actinobacillus actinomycetemcomitans-induced experimental periodontitis: host protection and tissue destruction. Clin Exp Immunol. 2006;147(1):128-38.

Garlet GP, Martins W Jr, Fonseca BAL, Ferreira BR, Silva JS. Matrix mettalloproteinases, their physiological inhibitors and osteoclast factor are differentially regulated by the cytokine profile in human periodontal disease. Jornaul Clin Periodontal. 2004;31(8):671-9.

Garlet GP, Cardoso CR, Silva TA, Ferreira BR, Avila-Campos MJ, Cunha FQ. Cytokine pattern determines the progression of experimental periodontal disease induced by Actinomycetemcomitans through the modulation of MMPs, RANKL, and their physiological inhibitors. Oral Microbol immunol. 2006;21(2):12-20.

Garlet GP, Cardoso CR, Campelli AP, Garlet TP, Avila-Campos MJ, Cunha FQ, Silva JS. The essential role of IFN-gamma in the control of lethal Aggregatibacter actinomycetemcomitans infection in mice. Microbes Infect. 2008;10(5):489-96.

Gelskey, S. C. Cigarette smoking and periodontitis: methodology to assess the strength of evidence in support of a causal association. Community Dent Oral Epidemiol. 1999;27(1):16-24.

Genco RJ, Grossi SG, Ho A, Nishimura F, Murayama Y. A proposed model linking inflammation to obesity, diabetes and periodontal infections. J Periodontol. 2005;76:2075-84.

Gerl V, Lischka A, Panne D, BroBmann P, Berthold R, Hoyer BF, Biesen R, Bruns A, Alexander T, Jacobi A, Dorner T, Burmester GR, Radbruch A, Hiepe F. Blood dendritic cells in systemic lupus erythematosus exhibit altered activation state and chemokine receptor function. Ann Rheum Dis. 2010;69(7):1370-7.

Gomez-Ambrosi J, Rodriguez A, Catalan V, Fruhbeck G. The bone-adipose axis in obesity and weight loss. Obes Surg. 2008;18:1134-43. 
Goralski KB. Chemerin, a novel adipokine that regulates adipogenesis and adipocyte metabolism. The Journal of biological chemistry. 2007;282(38) 28175-88.

Gorman A, Kaye EK, Nunn M, Garcia Rl. Changes in body weight and adiposity predict periodontitis progression in men. Journal Dent Res. 2012;91(10)921-6.

Graham KL. et al. Chemokine-like receptor- 1 expression by central nervous systeminfiltrating leukocytes and involvement in a model of autoimmune demyelinating disease. J Immunol, 2009;183(10):6717-23.

Greenburg AS, Obin MS. Obesity and the role of adipose tissue in inflammation and metabolism. Am J Clin Nutr. 2006;83:461-65.

Guimarães DED, Sardinha FLC, Mizurini DM, Tavares do Carmo MG. Adipocitocinas: uma visão do tecido adiposo. Rev. Nutr. 2007;20(5):549-559.

Haffajee AD, Socransky, SS. Relation of body mass index, periodontitis and Tannerella foysythia. J Clin Periodontol. 2009;36:89-99.

Hogan S, Canning C, Sun S, Sun X, Kadouh H, Zhou K. Dietary supplementation of grape skin extract improves glycemia and inflammation in diet-induced obese mice fed a western high fat diet. J Agric Food Chem. 2011;59:3035-41.

Hotamisligil GS, Shargill NS, Spiegelman BM. Adipose expression of tumor necrosis factor- $\alpha$ : direct role in obesity-linked insulin resistance. Science 1993;259:87-91.

lacopino AM. Diabetic periodontitis: possible lipid-induced defect in tissue repair through alteration of macrophage phenotype and function. Oral Dis. 1995;1(4):21429.

lannone F, Lapadula G. Chemerin/ChemR23 pathway: a system beyond chemokines. Arthritis Res Ther. 2011;13(2):104.

Irie K, Zalzal S, Ozawa H, McKee MD, Nanci A. Morphological and immunocytochemical characterization of primay osteogenic cell cultures derived from fetal rat cranial tissue. Anat Rec. 1998;252:554-67. 
Jin J, Machado ER, Yu H, Zhang X, Lu Z, Li Y, Lopes-Virella MF, Kirkwood KL, Huang Y. Simvastatin inhibits LPS-induced alveolar bone loss during metabolic syndrome. J Dent Res. 2014;93(3):294-9.

Johnson RB, Serio FG. Leptin within healthy and diseased human gingival. J Periodontol. 2001;72:1254-57.

Junqueira LCU, Carneiro J. Histologia Básica. 9a ed. Rio de Janeiro: Guanabara Koogan. 1999:474.

Karmiris K, Koutroubakis IE, Xidakis C, Polychromaki M, Voudouri T, Kouroumalis EA. Circulation levels of leptina, adiponectina, resistin, an ghrelin in inflammatory Bowel Disease. Inflamm. Bowel. Dis. 2006;12(2):100-105.

Kaur J, Adya R, Tan BK, Chen J, Randeva HS. Identification of chemerin receptor (ChemR23) in human endothelial cells: chemerin-induced endothelial angiogenesis. Biochem Biophys Res Commun. 2010;391(4):1762-8.

Khader YS, Bawadi HA, Haroun TF, Alomari M, Tayyem RF. The association between periodontal disease and obesity among adults in Jordan. J Clin Periodontol. 2009;36:18-24.

Kim EJ, Jin BH, Bae KH, B. Periodontitis and obesity: a study of the Fourth Korean National Health and Nutrition Examination Survey. J Periodontol. 2011;82:533-42.

Kinane DF, Lappin DF. Clinical, pathological and immunological aspects of periodontal disease. Acta Odontol Scand. 2001;59(3):154-60.

Kougias $\mathrm{P}$, Chai $\mathrm{H}$, Lin $\mathrm{PH}$, Yao Q, Lumsden AB, chen C. Effects of adipocytederived cytokines on endothelial functions: Implication of vascular disease. J. Surg Res. 2005;126(1):121-9.

Kraus D, Winter J, Jepsen S, Jager A, Meyer R, Deschner J. Interactions of Adiponectin and Lipopolysaccharide from Porphyromonas gingivalis on Human Oral Epithelial Cells. PLoS ONE. 2012;7(2):30716. 
Kukla M, ZwirsKa-Korczala K, Gabriel A, Waluga M, Warakomska I, Szczgiel B, Berdowska A, Mazur W, Wozniak-Grygiel E, Kryczka W. Chemerin, vaspin and insulin resistance in chronic hepatitis C. J Viral Hepat. 2010;17(9):661-7.

Liu J, Duan J, Wang Y, Ouyang X. Intracellular adhesion-1 is regulated by Porphyromonas gingivalis through nucleotide binding oligomerization domaincontaining proteins 1 and 2 molecules in periodontal fibroblasts. Jounal of Periodontology. 2014;85(2):358-68.

Liu KZ, Duarte PM, Santos VR, Xiang X, Xu M, Miranda TS, Fermiano D, Gonçalves TE, Sowa MG. Assessment of tissue oxigenation of periodontal inflammation in smokers using optical spectroscopy. Journal of Clinical Periodontology. 2014;41(4):340-7.

Loesche WJ. Bacterial mediators in periodontal disease. Clin Infect Dis. 1993;16:203-10.

López IP, Marti A, Milagro FI, Zulet Md Mde L, Moreno-Aliga MJ, Martinez JA. DNA microarray analysis of genes differentially expressed in diet-induced (cafeteria) obese rats. Obes Res. 2003;11(2):188-94.

Luangsay S, Wittamer V, Bondue B, De Henau O, Rouger L, Brait M, Franssen JD, Nadai P, Huaux F, Parmentier M. Mouse ChemR23 is expressed in dendritic cell subsets and macrophages, and mediates an anti-inflammatory activity of chemerin in a lung disease model. J Immunol. 2009;183(10):6489-99.

Luo XH, Guo LJ, Yuan LQ et al. Adiponectin stimulates human osteoblasts proliferation and differentiation via the MAPK sinaling pathway. Exp Cell Res. 2005;309:99-109.

MacDougald OA, Burant CF. The Rapidly Expanding Family of Adipokines. Cell Metab. 2007;6(3):159-61.

Mauer MM, Harris RB, Bartness TJ. The regulation of total body fat: lessons learned from lipectomy studies. Neurosci Biobehav Ver. 2001;25(1):15-28. 
Michalowicz BS, Diehl SR, Gunsolley JC, Sparks BS, Brooks CN, Koertge TE, et al. Evidence of a substantial genetic basis for risk of adult periodontitis. Journal of Periodontology. 2000;71(11):1699-707.

Moulin CM, Marguti I, Peron JP, Rizzo LV, Halpern A. Impact of adiposity on immunological parameters. Arq. Bras. Endocrinol. Metab. 2009;53(2):183-189.

Muruganandan S, Roman AA, Sinal CJ. Adipocyte differentiation of bone marrowderived mesenchymal stem cells: cross-talk with the osteoblastogenic program. Cell Mol Life Sci. 2009;66:236-53.

Naderali EK, Brown MJ, Pickavance LC, Wilding JP, Doyle PJ, Williams G. Dietary obesity in the rat induces endothelial dysfunction without causing insuling resistance: a possible role for triacylglycerols. Clin Sci. 2001;101(5):499-506.

Naderali EK, Williams G. Prolonged endothelial-dependent and -independent arterial dysfunction induced in the rat by short-term feeding with a high-fat, high-sucrose diet. Atherosclerosis. 2003;166(2):253-9.

Nanci A, Zalzal S, Gotoh Y, McKee MD. Ultrastructural characterization and immunolocalization of osteopontin in rat calvarial osteoblast primary cultures. Microsc Res Tech. 1996;33:214-31.

$\mathrm{Ng}$ SK, Leung WK. A community study of periodontal attachment loss in smokers. International Dental Journal. 2008a;58(5):243-6.

Ng SK, Leung WK. A community study on the relationship pf dental anxiety with oral health status and oral health-related quality of life. Community Dentistry and Oral Epidemiology. 2008b;36(4):347-56.

Nicolson GL. Metabolic syndrome and mitochondrial function: molecular replacement and antioxidant supplements to prevent membrane peroxidation and restore mitochondrial function. J Cell Biochem. 2007;100:1352-69.

Nisoli E, Clementi E, Carruba MO, Moncada S. Defective mitochondrial biogenesis: a hallmark of the high cardiovascular risk in the metabolic syndrome? Circ Res. 2007;6:795-806. 
Oshima K, Nampei A, Matsuda M, Iwaki M, Fukuhara A, Hashimoto J, Yoshikawa H, Shimomura L. Adiponectin increases bone mass by suppressing osteoclast and actiating osteoblast. Biochem Biophys Res Commun. 2005;331:520-26.

Okazaki R, Inoue D, Shibata M, et al. Estrogen promotes early osteoblast differentiation and inhibits adipocyte differentiation in mouse bone marrow stromal cell lines that express estrogen receptor (ER) a or b. Endocrinology. 2002;143:234956.

Olney JW. Brain lesions, obesity and other disturbances in mice treated with monosodium glutamate. Science. 1969;164(3880):719-21.

Ouch N, Parker JL, Lugus JJ, Walsh, K. Adipokines in inflammation and metabolic disease. Nat Rev Immunol. 2011;11:85-97.

Ozcan E, Saygun NI, Serdar MA, Kurt N. Evaluation of the salivary levels of vistatin, chemerin, and progranulin in periodontal inflammation. Clin Oral Investig. 2015;19(4):921-8.

Page RC, Kornman KS. The pathogenesis of human periodontitis: an introduction. Periodontol 2000. 1997;14(1):9-11.

Parmentier M, Cammuni D. Specific recruitment of antigen-presenting cells by chemerin, a novel processed ligand from human inflammatory fluids. J Exp Med. 2003;198(7):977-85.

Parolini S, Santoro A, Marcenero E, Luini W, Massardi L, Facchetti F, Communi D, Parmentier M, Majorana A, Sironi M, Tabellini G, Moretta A, Sozzani S. The role of chemerin in the colocalization of NK and dendritic cell subsets into inflamed tissues. Blood. 2007;109(9):3625-32.

Pataro AL, Costa FO, Cortelli SC, Cortelli JR, Abreu MHNG, Costa J. Association between severity of body mass index and periodontal condition in women. E Clin Oral Invest. 2012;16:727-34.

Perlstein MI, Bissada NF. Infuence of obesity and hypertension on the severity of periodontitis in rats. Oral Surg Oral Med Oral Pathol. 1977;43:707-19. 
Peruzzo DC, Benatti BB et al. A systematic review of stress and psychological factors as possible risk factors for periodontal disease. J Periodontol. 2007;78(8):1491-504.

Pichon N, Heng N, Bernimoulin JP, Kleber BM, Willich SN, Pitchon T. Obesity, inflammation, and periodontal disease. J Dent Res. 2007;86:400-9.

Polonsky KS, Given BD, Hirsch L, Shapiro ET, Tillil H, Beebe C, et al. Quantitative study of insulin secretion and clearance in nor- mal and obese subjects. J Clin Invest. 1988;81:435-41.

Pond C. Ecology of storage and allocation of resources: animals. Encyclopedia of Life Sciences. 2001;1-5.

Prates TP, Taira TM, Holanda MC, Bignardi LA, Salvador SL, Zamboni DS, Cunha FQ, Fukada SY. NOD2 contributes to Porphyromonas gingivalis-induced bone resorption. J dent Res. 2014;93(11):1155-62.

Preshaw PM, Taylor JJ. How has research into cytokine interactions and their role in driving immune responses impacted our understanding of periodontitis? J Clin Periodontol. 2011;38:60-84.

Qiu W, Andersen TE, Bollerslev J, Mandrup S, Abdallah BM, Kassem M. Patients with high bone mass phenotype exhibit enhanced osteo-blast differentiation and inhibition of adipogenesis of human mesenchymal stem cells. J Bone Miner Res. 2007;22:1720-31.

Queiroz-Junior CM, Madeira MF, Coelho FM, de Oliveira CR, Candido LC, Garlet GP, et al. Experimental arthritis exacerbates Aggregatibacter actinomycetemcomitans-induced periodontitis in mice. Journal of clinical periodontology. 2012;39(7):608-16.

Ribeiro Filho FF, Marisa LS, Ferreira SRG, Zanella MT. Gordura visceral e síndrome metabólica: mais que uma simples associação. Arq Bras Endocrinol Metab. 2006;50(2):230-38.

Ritchie CS. Obesity and periodontal disease. Periodontology. 2007;44:154-163. 
Roh SG, Song SH, Choi KC, Katoh K, Wittamer V, Parmentier M, Sasaki S. "Chemerin-A new adipokine that modulates adipogenesis via its own receptor." Biochem Biophys Res Commun. 2007;362(4):1013-18.

Roman AA, Parlee SD, Sinal CJ. Chemerin: a potential endocrine link between obesity and type 2 diabetes. Endocrine. 2012;42(2):243-51.

Rosa AL, Beloti MM. TAK-778 enhances osteoblast differentiation of human boné marrow cell. J Cell Biochem. 2003;89:1148-53.

Rosmond R. Aetiology of obesity: a striving after wind? Obes. Rev. 2004;5:177-81.

Saito T, Shimazaki Y, Kiyohara Y, Kato I, Kubo M, lida M, Yamashita Y. Relationship between obesity, glucose tolerance, and periodontal disease in Japanese women: the Hisayama study. J Periodontal Res. 2005;40(4):346-53.

Saito T, Shimazaki Y, Sakamoto M. Obesity and periodontitis. N Engl J Med. 1998;339:482-3.

Saito T, Shimazaki Y, Koga T, Tsuzuki M, Ohshima A. Relationship between upper body obesity and periodontitis. J Dent Res. 2001;80:1631-36.

Salekzamani Y, Shirmohammadi A, Rahbar M, Shakouri S, Nayebi F. Association between human body composition and periodontal disease. Disponível em: http://www.ncbi.nlm.nih.gov/pmc/articles/ PMC3216386/. Acesso em: 28/04/2015.

Sambrook J, Russel DW. Molecular cloning: a laboratory mannual, Editora Cold Spring Harbor, N.Y.: Cold Spring Harbor Laboratory Press, 2001.

Sánchez-Muñoz F, García-Macedo R, Alarcón-Aguilar F, Cruz M. Adipocinas, tejido adiposo y su relación con células del sistema immune. Gazeta Medica de Mexico. 2005;141(6):505-12. 
Sasaki H, Okamatsu Y, Kawai T, Kent R, Taubman M, Stashenko P. The interleukin10 knockout mouse is highly susceptible to Porphyromonas gingivalis-induced alveolar bone loss. Journal of Periodontal Research. 2004;39(6):432-41.

Sasaki H, Suzuki N, Kent R, Kawashima N, Takeda J, Stashenko P. T Cell Response Mediated by Myeloid Cell-Derived IL-12 Is Responsible for Porphyromonas gingivalis-Induced Periodontitis in IL-10-Deficient Mice. J Immunol. 2008;180(9):6193-8.

Sasaki H, Suzuki N, Alshwaimi E, Xu Y, Battaglino R, Morse L, Stanhenko P. 18ßGlycyrrhetinic acid inhibits periodontitis via glucocorticoid-independent nuclear factor$\mathrm{KB}$ inactivation in interleukin-10-deficient mice. Journal of Periodontal Research. 2010;45(6):757-63.

Shah P. Insulin resistance (IR) in impaired glucose tolerance (IGT). Int. J Diab Dev Countries. 1996;16:16-8.

Schreyer SA, Wilson DL, LeBoeuf RC. C57BL/6 mice fed high fat diets as models for diabetes-accelerated atherosclerosis. Atherosclerosis. 1998;136:17-24.

Shuldiner AR, Yang R, Gong DW. Resistin, obesity and insulin resistance-the emerging role of the adipocyte as an endocrine organ. The New England Journal of Medicine. 2001;345(18):1345-6.

Simch RP, Gaio EJ, Rösing CK. Effect of body weight in the pathogenesis of ligatureinduced periodontal disease in Wistar rats. Acta Odontol Scand. 2008;66:130-4.

Souza AB, Chambrone L, Okawa RTP, Silva CO, Araujo MG. A obesidade como fator de risco para doença periodontal: revisão de literatura. Ver Dental Press Period Implant. 2010;4(3):74-82.

Speakman J., Hambly C, Mitchell S, Krol E. Animal models of obesity. Obes Rev. 2007;8(1):55-61.

Stejskal D, Karpisek M, Hanulova Z, Svestak M. Chemerin is an independent marker of the metabolic syndrome in a Caucasian population a pilot study. Biomedical papers of the Medical Faculty of the University Palacky, Olomouc, Czechoslovakia. 2008;152(2):217-21. 
Takahashi M, Takahashi Y, Takahashi K, Zolotaryov FN, Hong KS, Kitazawa R, Lida K, Okimura Y, Kaji H, Kitazawa S, Hasuga M, Chihara K. Chemerin enhances insulin signaling and potentiates insulin- stimulated glucose uptake in 3T3-L1 adipocytes. FEBS Lett. 2008;582(5):573-8.

Taylor GW, Burt BA, Becker MP, Genco RJ, Shlossman M, Knowler WC, Pettitt DJ. Non-insulin dependent diabetes mellitus and alveolar bone loss progression over 2 years. J Periodontol. 1998;69(1):76-83.

Tezal M, Grossi SG, et al. Alcohol consumption and periodontal disease. The Third National Health and Nutrition Examination Survey. J Clin Periodontol. $2004 ; 31(7): 484-8$.

Thomas T, Gori F, Khosla S, Jensen MD, Burguera B, Riggs BL. Leptin acts on human marrow stromal cells to enhance differentiation to osteoblasts and to inhibit differentiation to adipocytes. Endocrinol. 1999;140:1630-38.

Verzeletti GN, Gaio EJ, Linhares DS, Rosing CK. Effect of obesity on alveolar bone loss in experimental periodontitis in Wistar rats. Journal Appl Oral Sci. 2012;20(2):218-21.

Zabel BA, Allen SJ, Kulig P, Allen JA, Cichy J, Handel TM, Butcher EC. Chemerin activation by serine proteases of the coagulation, fibrinolytic, and inflammatory cascades. J Biol Chem. 2005;280(41):34661-6.

Zhou X. Effect of sex and age on serum biochemical reference ranges in C57B16J mice. Comp Med. 2004;54:176-178.

Zhu M, Belkina AC, DeFuria J, Carr JD, Van Dyke TE, Gyurko R, Nikolajczyk BS. B cells promote obesity-associated periodontitis and oral pathogen-associated inflammation. Journal of Leukocyte Biology. 2014;96(2):349-57.

Zimmermann GS, Bastos MF, Gonçalves TED, Chambrone L, Duarte PM. Local and circulation levels of adipocytokines in obese and normal weight individuals with chronic periodontitis. Jornal of Periodontology. 2013;84(5):624-33. 
Yamaguchi N, Hamachi T, Kamio N, et al. Expression levels of adiponectin receptors and periodontitis. J Periodontal Res. 2010;45:296-300.

Yamawaki H. Vascular effects of novel adipocytokines: focus on vascular contractility and inflammatory responses. Biol Pharm Bull. 2011;34(3):307-10.

Yokota T, Meka CSR, Medina KL, Igarashi H, Comp PC, Takahashi M, Nishida M, Oritani K, Miyagawa J, Funahashi T, Tomiyama Y, Matsuzawa Y, Kincade PW. Paracrine regulation of fat cell formation in bone marrow cultures via adiponectin and prostaglandins. J Clin Invest. 2002;109:1303-10.

Yoshinaka K, Shoji N, Nishioka T, Sugawara Y, Hoshino T et al. Increased interleukin-18 in the gingival tissues evokes chronic periodontitis after bacterial infection. The Tohoku journal of experimental medicine. 2014;232(3):215-22.

Wajchenber BL, Nery M, Cunha MR, Silva MER. Adipose tissue at the crossroads in the development of the metabolic syndrome, inflammation and atherosclerosis. Arq. Bras. Endocrinol. Metab. 2009;53(2):145-50.

Wang L, Wang J, Jin Y, Gao H, Lin X. Oral administration of all-Trans Retinoic Acid Supresses Experimental Periodontitis by Modulation the Th17/Treg Imbalance. Journal of Periodontology. 2013;85(5):740-50.

Weigert J, Obermeier F, Neumeier M, Wanninger J, Filaesky M, Bauer F, Aslanidis C, Rogler G, Ott C, Schaffler A, Scholmerich J, Buechler C. Circulating levels of chemerin and adiponectin are higher in ulcerative colitis and chemerin is elevated in Crohn's disease. Inflamm Bowel Dis. 2010;16(4):630-7.

Wilensky A, Polak D, Houri-Haddad Y, Shapira L. The role of RgpA in the pathogenicity of Porphyromonas gingivalis in the murine periodontitis model. Journal of Clinical Periodontology. 2013;40(10):924-32.

WHO - World Health Organization. Obesity: Preventing and managing the Global Epidemic - Report of a WHO Consultation on Obesity, Geneva, 1997.

WHO - World Health Organization. Obesity and overweight. Disponível em : http:/www.who.int/mediacentre/factsheets/fs311/en/index.html., 2015. 
Wittamer V, Franssen JD, Vulcano M, Mirjolet JF, Le Poul E, Migeotte I, Brezillon

Wittamer V, Gregoire F, Robberecht P, Vassart G, Communi D, Parmentier M. The C-terminal nonapeptide of mature chemerin activates the chemerin receptor with low nanomolar potency. J Biol Chem. 2004;279(11):9956-62.

Wozniak SE, Gee LL, Wachtel MS, Frezza EE. Adipose tissue: the new endocrine organ? A review article. Dig Dis Sci. 2009;54:1847-56. 
Anexo 



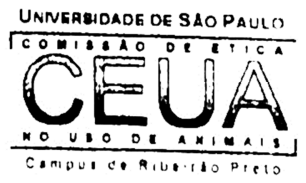

\section{UNIVERSIDADE DE SÃO PAULO \\ Campus de Ribeirăo Preto \\ Comissa de Etica no Uso de Animais}

\section{E R T I F I C A D O}

Certificamos que o trabalho (Protocolo $n^{\circ}$ 12.1.1783.53.3), intitulado "Adipocina Chemerin - Estudo em Cultura de Células da Linhagem Osteoblástica e na Doença Periodontal de Camundongos Normais e Obesos", de autoria de Giselle de Angelo Leite Carbonaro Guerreiro e de Léa Assed Bezerra da Silva, por estar de acordo com os Princípios Éticos na Experimentação Animal adotado pela Comissão de Ética no Uso de Animais (CEUA) do Campus de Ribeirão Preto - USP foi aprovado em reunião da CEUA de 04.03.2013.

Colaboradores: Sandra Yasuyo Fukuda Alves

This is to certify that the work (Protocol number 12.1.1783.53.3), entitled: "'Adipocina Chemerin - Estudo em Cultura de Células da Linhagem Osteoblástica e na Doença Periodontal de Camundongos Normais e Obesos"', by Giselle de Angelo Leite Carbonaro Guerreiro and Léa Assed Bezerra da Silva, is in accordance with the Ethic Principles in Animal Experimentation adopted by Ethic Commission for the Use of Animals (CEUA) of the Campus of Ribeirão Preto - USP, and was approved in the meeting, March, 042013.

Ribeirão Preto, 8 de março de 2013.

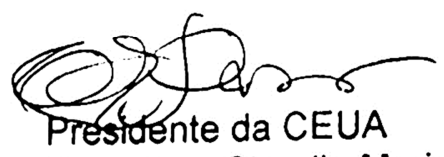

Profa.Dra. Claudia Maria Padovan

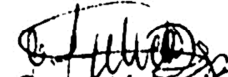

Secretária d CEUA

Maria Angélica Depiro

Av. Bandeirantes, 3900 - CEP 14040-900 - RIboirlo Proto - SAlo Paulo Fone: (16) 36024469 - Fax: (16) 36337964 